\title{
Evolution and stability of 2-mercaptobenzimidazole inhibitor film upon Al alloy 6061
}

\author{
Mohd Rafiuddin Jakeria ${ }^{1} \cdot$ Rou Jun Toh ${ }^{1} \cdot$ Xiao-Bo Chen $^{1} \cdot$ Ivan S. Cole $^{1,2}$ (D)
}

Received: 4 September 2021 / Accepted: 6 February 2022 / Published online: 4 March 2022

(c) Crown 2022

\begin{abstract}
Organic corrosion inhibitors have become competent alternatives to hazardous chrome conversion coatings due to their rapid adsorption over metal surfaces in corrosive environments. Literature suggests a wide range of organic corrosion inhibitors with high inhibition efficiency, barrier properties, and adsorption mechanisms. However, the long-term durability and protectiveness of an organic inhibitor film need to be understood with in-depth insights on its interaction with heterogenous alloy surfaces like AA6xxx, reduction of galvanic activities and time-resolved degradation due to ionic diffusion. The present article is focused on the time-resolved adsorption and degradation of 2-mercaptobenzimidazole (2-MBI)-induced inhibitor layer/film over AA6061 in $0.1 \mathrm{M} \mathrm{NaCl}$ solution. Electrochemical and surface analysis data indicate that the presence of 2-MBI drives the rapid formation of a 20-30 nm thick protective film comprised of constitutional elements of C, S, and N from 2-MBI upon the surface of AA6061 substrate. This film mitigated the corrosion cells associated with nano- and microsized $\mathrm{Fe}$ and Si-rich intermetallic particles (IMPs) in AA6061. XPS reveals two distinguished bonding states of S and N in the inhibitor film and chemical interactions between 2-MBI and the surface of AA6061. The protective film maintained $65 \%$ inhibiting efficiency after 1 day, which progressively degraded due to electrolyte ingress and eventually with a drop in inhibition efficiency down to $21 \%$ after 14 days. Inhibitor-induced film over AA6061 reduced the corrosion susceptibility of Fe, and Si-rich IMPs up to 1 day given the subsequent adsorption by $\mathrm{S}$ and $\mathrm{N}$ heteroatoms. However, this film became thick and defective after 1 day, which undermined its barrier properties against ingress of aggressive ions and facilitated water adsorption.
\end{abstract}

Ivan S. Cole

ivan.cole@rmit.edu.au

1 School of Engineering, RMIT University, Melbourne, Australia

2 Research Capability, RMIT University, Melbourne, Australia 


\section{Graphical abstract}

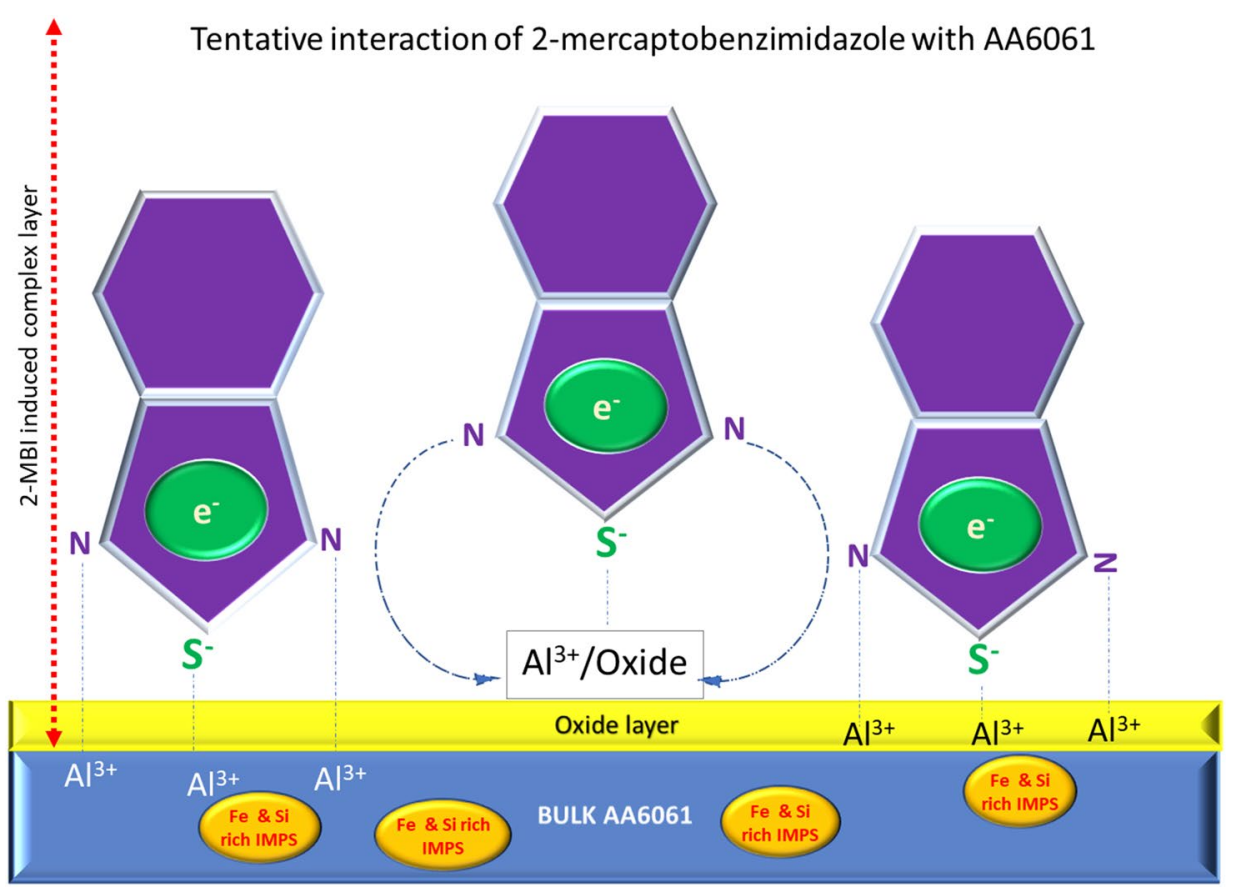

Keywords Aluminum alloy $6061 \cdot$ Durability $\cdot$ Adsorption $\cdot 2$-MBI $\cdot$ Corrosion inhibition

\section{Introduction}

Organic film-forming corrosion inhibitors are popular with coating technologies for their rapid adsorption over metal surfaces. Over the last decades, these have been extensively studied to protect heterogenous $\mathrm{Al}$ alloys as conventional chrome conversion coatings are hazardous to human health and the environment [1-5]. However, a limited number of studies reported the inhibitory efficiency of corrosion inhibitors on high-strength $\mathrm{Al}$ alloys 6xxx (AA6xxx) series [6-11], and the adsorption and durability of organic corrosion inhibitors in corroding environments need to be well understood. Comprehensive and in-depth investigation of film-forming organic inhibitors is required to understand film thickness, film chemistry, and the consequent barrier properties of an inhibitor film over an extended period [9, 10]. It is critical to understand inhibitor interactions with an oxide layer and other available surface species, the breakdown mechanism of established inhibitor film and the role of ionic diffusion therein, and the changing coverage IMPs of inhibitors and the impact of such coverage on micro galvanic or nano galvanic couplings [12, 13]. Systematic studies on the long-term behavior of such inhibitor systems in terms of film stability, durability, and breakdown should address existing knowledge gaps and develop sound systems with inhibitor layers promoting sustained inhibition efficiency.
AA6xxx possesses better corrosion resistance than their high-strength $\mathrm{Al}$ alloy counterparts, even given the presence of several IMPs within the Al matrix [14-16]. These IMPs are categorized as coarse constituent $\mathrm{AlFeMnSi}$ ( $\alpha$-phase), metastable or stable precipitates of $\mathrm{Mg}_{2} \mathrm{Si}$ ( $\beta$-phase), pure Si particles, $\mathrm{Al}_{5} \mathrm{Cu}_{2} \mathrm{Mg}_{8} \mathrm{Si}_{6}$ (Q-phase), $\mathrm{Al}_{2} \mathrm{Cu}$ ( $\theta$-phase), and $\mathrm{Al}_{2} \mathrm{CuMg}$ (S-phase), respectively. Most of these IMPs are either cathodic or anodic to the surrounding $\mathrm{Al}$ matrix and can initiate pitting in the adjacent matrix [17-19]. It has been reported that $\mathrm{Mg}_{2} \mathrm{Si}$ acts as an "anode" owing to the anodic corrosion potential to Al. Therefore, these IMPs preferentially dissolve with respect to the $\mathrm{Al}$ matrix in neutral and acidic $\mathrm{NaCl}$ solutions [15, 20-22]. In alkaline $\mathrm{NaCl}$ solutions ( $\mathrm{pH}>12), \mathrm{Mg}_{2} \mathrm{Si}$ exhibits passivity and turns into "cathode", and Al matrix becomes anode [14]. Cathodic partial reactions could facilitate $\mathrm{OH}^{-}$(hydroxyl ion) generation and subsequent rise in $\mathrm{pH}[23,24]$. Given the amphoteric nature of aluminium oxides, high $\mathrm{pH}$ values degrade oxide layers and thus expose bulk $\mathrm{Al}$ for further anodic dissolution. Therefore, Al matrix preferentially dissolves at the periphery of $\mathrm{Mg}_{2} \mathrm{Si}$ in AA6xxx. A good number of publications have confirmed that $\mathrm{Mg}_{2} \mathrm{Si}$ dissolves by preferential $\mathrm{Mg}$ dissolution, which leaves Si-rich remnant that is immune to further corrosion reactions $[14,22,25,26]$. Therefore, providing a barrier effect could be helpful to reduce the galvanic activity of IMPs where film-forming organic corrosion inhibitors 
could play a key role by rapidly adsorbing over IMPs in corrosive environments and mitigating the overall corrosion rate of AA6xxx. Limiting IMP activities by organic inhibitor adsorption has been minimally reported in the literature for AA6xxx $[9,27]$.

The critical issues addressed in most inhibitor studies include reducing corrosion current density, enhanced polarization resistance, and the existence of non-ideally behaved capacitance of inhibitor films/layers [28-33]. The electrical parameters associated with an inhibitor-induced protective layer could provide a quantitative view of the corrosion resistive properties of an applied inhibitor. Alterations of these parameters in long durations tests (up to 14 days) could be crucial in understanding the surface reactions occurring on the substrate surface. The resistance offered by an inhibitor-derived layer could be represented by multiple resistive elements that are summed up to calculate the polarization resistance of the system, which is one of the indicators of long-term durability [34]. Therefore, time-resolved changes of polarization resistance coupled could provide critical information about the inhibitor coverage above the substrate surface and subsequent diffusion of aggressive ions through an inhibitor layer/coating. The constituent parameters of polarization resistance need to be discussed individually for a deeper understanding of the durability of corrosion inhibition. For instance, a barrier against charge transfer of a working electrode refers to the resistance of a metal-coating interface against ionic diffusion and desorption of water molecules $[35,36]$. Charge transfers resistance $\left(R_{\mathrm{ct}}\right)$ is one of the important parameters to look at during electrochemical analysis over the long-term, which has been minimally reported for AA6xxx [9, 27]. Moreover, capacitive elements of an electrochemical system represent the homogeneity of its coverage over a substrate surface. It could be predicted to some extent by the ideality of respective quantified parameters [37]. Therefore, the deviation of capacitive elements from the behavior of an ideal capacitor with time needs to be taken into consideration during electrochemical analysis.

A large number of literatures on corrosion inhibition focused on the exposure of metal substrate directly to inhibited electrolyte and then measured electrochemical parameters at different periods [38-41]. In most of these studies, the working electrode was exposed to inhibited electrolyte, and electrochemical data were acquired at different time intervals to evaluate any inhibitor-induced layer's inhibition effect and barrier properties. However, the interactions of inhibitor molecule with working electrode could be different if it is exposed inhibitor-treated corrosive electrolyte without any external electrical connections, i.e. three cell electrode arrangements. Therefore, time-resolved growth monitoring could be more reliable if alloy substrate is exposed to inhibited electrolyte solution and then pulled out from that environment periodically, followed by electrochemical measurements using an electrolyte solution without inhibitor. Remarkably, this aspect has not been well reported in the open literature. Furthermore, the electrochemical properties of an inhibitor layer/coating critically depend on the adsorption criterion of inhibitor molecules, its influence on reducing the nano and micro galvanic activities around IMPs, and time-dependent change in the coating/layer thickness and composition.

Heterocyclic organic compounds have been numerously reported for corrosion mitigation of $\mathrm{Cu}, \mathrm{Au}$, and $\mathrm{Fe}$ alloys. The adsorption mechanisms have been explained by the interaction of electron-rich ligands with bulk metal [39, 42-44]. Azole-based heterocyclics, especially 2-MBI, have attracted corrosion researchers' interest due to their rapid film-forming behaviour over $\mathrm{Cu}$-rich IMPs of aerospacegrade AA2024 alloy [45-48]. The growth and stability of 2-MBI film that forms over a metal or alloy substrate could vary as a function of the chemical nature of the electrolyte, interactions between inhibitor molecules with substrate oxide, and exposure time. Cu-free AA6xxx alloys constitute $\mathrm{Fe}, \mathrm{Si}$, and $\mathrm{Mn}$-rich intermetallic phases. Therefore, the adsorption of 2-mercaptobenzimidazole (2-MBI) molecules could be investigated for any distinguishable change in bonding from the topmost inhibitor layer to the innermost metal-inhibitor layer interface. Previously, inhibitor adsorption mechanisms on AA6xxx alloys and the influence of IMPs have been explored with an exposure time ranging from 0 to $168 \mathrm{~h}$. However, those studies were confined mainly to inorganic inhibitors $[49,50]$. In addition, limited studies have been conducted on organic inhibitors at shorter exposure times (less than $168 \mathrm{~h}$ ) [9, 27]. It is unclear about the growth of a barrier layer by 2-MBI in a corrosive environment. A deep understanding of the mechanisms of inhibitor film growth, stability, and breakdown is beneficial to develop and optimize inhibitor systems for extended use and enhanced durability [51]. Quantum chemical calculations postulate that 2-MBI inhibitor film could have a thickness of $0.75-1 \mathrm{~nm}$ when attached to a $\mathrm{Cu}$ substrate in a perpendicular orientation within a single layer [52]. However, in real-time conditions, adsorption of organic inhibitor molecules may result in a complex film over a metal substrate due to the presence of a metal oxide layer and electrolyte ions [48, 53, 54].

An inhibitor film could be a combination of available surface species like oxygen or ions from dissolved IMPs, metal matrix, electrolyte, etc. [12, 13]. Available knowledge on 2-MBI inhibitor layer is insufficient to address some key factors when applied on AA6xxx [48, 53, 54]. These key factors could be the growth of a protective layer in the presence of 2-MBI molecules or barrier properties of that layer against diffusion of electrolyte. Additionally, desorption/adsorption of 2-MBI molecules calculated on relevant electrical 
parameters and the durability of inhibition due to degeneration of the protective layer could also be useful.

Figure 1 hypothetically represents the film formation by an organic inhibitor molecule with a metal surface by interacting with heteroatoms and its breakdown at a longer exposure time. The left-hand side of the figure tentatively depicts the bond formation of an organic inhibitor molecule with a metal surface where the first interaction has been predicted through the bond formation by heteroatoms simultaneously with the metal or metal oxide. A second interaction could also be possible by the physical adsorption of inhibitor molecules, resulting in a complex multilayer film structure. Heterocyclic organic inhibitor molecules have different heteroatoms that could draw the benzene ring's electron clouds towards them and act as charge centers $(X$, $Y \& Z$ from Fig. 1). These charge centers then facilitate weak electrostatic interaction with the underlying metal or oxide, resulting in physical adsorption of inhibitor molecules through Vander walls force $[55,56]$. Subsequent chemical and physical adsorption of inhibitor molecules could result in a complex, multilayered structure over the substrate surface that may vary over time in bonding environments of heteroatoms [56-60]. This inhibitor film/layer could act as a barrier against charge transfer, i.e. higher polarization resistance, better hydrophobicity, etc. Mechanism of film formation and its structure could be predicted through the micro and nanoscopic surface analysis techniques with complementary electrochemical data. The structure of this film could be varied due to the chemical environment, charge density, and electrostatic interactions between an organic inhibitor molecule and substrate surface. This film/layer (right-hand side) could be porous and defective at longer exposure times due to breaking bonds with metal or oxide. It can be investigated through the quantitative analysis of electrochemical parameters. The available aggressive ions could penetrate this defective layer and accelerate further corrosion reactions at longer exposure times to corrosive electrolytes. In the case of a heterogeneous alloy surface, the formation of an inhibitor film/layer and its degradation with time could be critical due to inhomogeneous surface potential distribution across the surface. Therefore, the knowledge on the mechanism of inhibitor film formation over AA6061 and its durability in a corrosive electrolyte for a longer time could be valuable to current literature.

The present study aims to determine the durability and inhibition mechanism of 2-mercaptobenzimidazole (2-MBI) on AA6061 in $0.1 \mathrm{M} \mathrm{NaCl}$ at room temperature. A key component to investigate is the interaction of 2-MBI molecules with AA6061 surface in terms of protective layer formation in a corrosive environment and establishment of barrier properties of 2-MBI to any electrolyte diffusion, interaction with any oxide layer formed, and the durability of the protective film over an exposure period of $14 \mathrm{~d}$. Changes in inhibitor performance with exposure time and the response heteroatoms of 2-MBI upon adsorption were investigated using a range of electrochemical and analytical techniques,

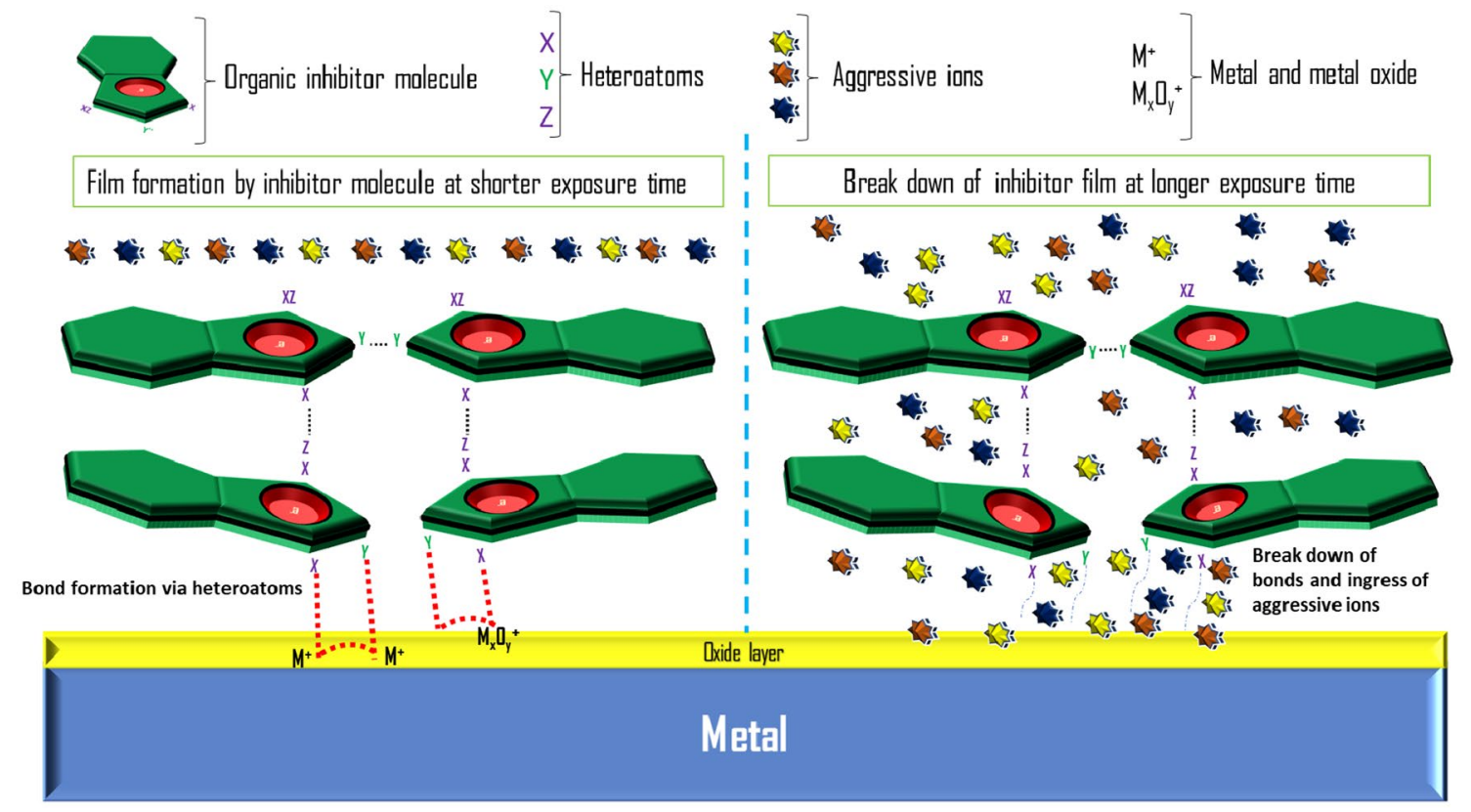

Fig. 1 Schematic illustration of inhibitor film formation and breakdown inhibitor film/layer over a metal surface in a corrosive electrolyte. Left side of the figure hypothetically presents the interaction of heteroatoms of an organic inhibitor molecule with metal and metal oxide at shorter exposure time. Right-hand side showcases the breakdown of bonds with inhibitor molecule and subsequent ingress of aggressive ions through the inhibitor film/layer at longer exposure time 
such as EIS, LPR, PDS and FIB-SEM EDS, TEM-EDS, and XPS etching.

\section{Experimental}

\subsection{Substrate preparation}

AA6061-T6 was used as substrate supplied by Calm Aluminum Pty., Melbourne. The nominal composition of the alloy provided by supplier includes $\mathrm{Mn}(0.10 \mathrm{wt} \%), \mathrm{Fe}$ (0.20 wt \%), $\mathrm{Mg}(0.80 \mathrm{wt} \%), \mathrm{Si}(0.70 \mathrm{wt} \%), \mathrm{Cu}(0.15 \%)$, $\mathrm{Zn}(0.02 \mathrm{wt} \%), \mathrm{Cr}(0.07 \%), \mathrm{Ti}(0.02 \%), \mathrm{Al}$ (Balance). Two sets of samples were prepared for electrochemical and surface analysis, respectively. Samples used for electrochemical analysis were cut from the AA6061-T6 rods and then thoroughly cleaned and degreased with acetone, followed by rinsing in deionized water. Samples for surface analysis were ground with Si carbide papers down to 4000 grit, followed by diamond polishing up to $0.25 \mu \mathrm{m}$ surface finish. Later samples were etched at $60{ }^{\circ} \mathrm{C}$ in $10 \%$ aqueous $\mathrm{NaOH}$ for $45 \mathrm{~s}$, followed by $30 \mathrm{~s}$ in concentrated nitric acid at room temperature to remove any surface modifications originated from polishing [9]. All polished samples were cleaned in deionized water, dried, and stored in a desiccator for further use.

\subsection{Static immersion and electrolyte solution preparation}

2-mercaptobenzimidazole $\left(\mathrm{C}_{7} \mathrm{H}_{6} \mathrm{~N}_{2} \mathrm{~S}\right)(99 \%)$ was sourced from Sigma-Aldrich (Australia). $\mathrm{NaCl}$ solution $(0.1 \mathrm{M})$ was used in this study, which was based on the fact that a large number of studies used $0.1 \mathrm{M}$ of $\mathrm{NaCl}$ solution as corrosion media to examine the inhibitor behaviour with respect to $\mathrm{Al}$ and its alloys [61-63]. 2-MBI was added to the prepared $\mathrm{NaCl}$ solution to a $10^{-3} \mathrm{M}$ constant concentration for static immersion. $10^{-3} \mathrm{M}$ has been identified as the solubility limit of 2-MBI in $\mathrm{NaCl}$ solution. This is the rationale that this concentration was chosen as the optimal concentration for the present work [57, 64, 65]. To maximize the aqueous solubility of 2-MBI, it was dissolved in $10 \mathrm{ml}$ water inside an ultrasonic bath. Followed by mixing drop by drop in saline solution to the desired concentration.

Both sets of samples (electrochemical and surface analysis) were immersed in blank and inhibited $\mathrm{NaCl}$ solution and removed periodically from the immersion chambers at day 1, 7 and 14, respectively. This would allow time-resolved comparisons between the inhibitory effect of 2-MBI and blank $\mathrm{NaCl}$ solution on AA6061 samples. Then samples were rinsed with deionized water and dried in a nitrogen air flow. Electrochemical and surface characterizations were performed on immersed samples afterward. The samples immersed in inhibited saline solution are termed "inhibited" and their counterparts immersed in blank saline solution as "uninhibited" hereafter.

\subsection{Electrochemical analysis}

Electrochemical tests were conducted by Biologic potentiostat with a conventional three electrode arrangement. A $\mathrm{Ag} / \mathrm{AgCl}$ electrode (with supersaturated $\mathrm{KCl}$ as electrolyte), a platinum mesh and AA6061 specimen were used as reference, counter, and working electrodes, respectively. The exposed area of the working electrode was $0.74 \mathrm{~cm}^{2}(1 \mathrm{~cm}$ in diameter). Open circuit potential (OCP) was stabilized for 90 min prior to the electrochemical measurements.

Cathodic potentiodynamic polarization tests were carried out over the voltage range of -0.7 to $+0.2 \mathrm{~V}$ vs $\mathrm{OCP}$, and anodic potentiodynamic polarization tests were performed within a voltage range of +0.7 to $-0.2 \mathrm{~V}$ vs OCP. The scan rate of $5 \mathrm{mV} / \mathrm{s}$ was employed on two different set of samples (different samples for cathodic and anodic scans). The chosen scan rate was faster than the usual for Tafel plots. However, this has been reported to be typical for $6 \mathrm{xxx}$ aluminum alloys [66, 67].

Polarization resistance $\left(R_{\mathrm{pol}}\right)$ measurements were conducted by the cyclic polarization technique. Measurements were taken every $2.5 \mathrm{~h}$ up to $22 \mathrm{~h}$. The test amplitude was $\pm 15 \mathrm{mV}$ relative to the OCP with a scan rate of $0.167 \mathrm{mV} \mathrm{s}^{-1}$.

Electrochemical impedance spectroscopy (EIS) was executed from a frequency range of $1 \mathrm{MHz}$ to $10 \mathrm{mHz}$, employing $10 \mathrm{mV}$ sinusoidal perturbation potential at OCP with 10 points per decade. EIS results were recorded every $3 \mathrm{~h}$ over $21 \mathrm{~h}$. EC-Lab version V 11.27 was used for data fitting. All electrochemical measurements were performed at room temperature. All the electrochemical tests were triplicated to maintain the reproducibility of data. Uninhibited and inhibited samples were taken for cross-sectional and surface analysis studies after immersion to respective solutions.

\section{$2.4 \mathrm{pH}$ measurements}

pH measurements were made on static immersion solutions with AA6061 samples using a Toledo $\mathrm{pH}$-meter at day 0 , 1,7 , and 14 to observe and record the change in $\mathrm{pH}$ values with time.

\subsection{Focus ion beam scanning electron microscopy \& EDS (FIB-SEM EDS)}

FIB-SEM images were taken at high magnifications (10 k to $850 \mathrm{k} \times$ ) using FIB milling by SCIOS FIB dual-beam SEM. The details of the technique have been reported in our previous article [16]. 
TEM lamellae were prepared from the inhibited AA6061 samples with FIB milling. A few selected zones were chosen randomly from the alloy surface, and Auto-TEM G2 mode was employed to prepare TEM-lamella. To protect surface layer present over the sample surface, $100 \mathrm{~nm}$ thick Pt layer was deposited over the selected areas by electron beam prior Auto-TEM procedure. The dimensions of TEM-lamella were set as $12 \mu \mathrm{m} \times 3 \mu \mathrm{m} \times 500 \mathrm{~nm}$ using a depth correction of $1.5 \mu \mathrm{m}$ and a final thickness of $2 \mu \mathrm{m}$. Polishing of the lamellae was conducted with a $\mathrm{Ga}$ ion beam at $30 \mathrm{kV}$ with $50 \mathrm{nA}$ beam current, which was finally reduced up to $10 \mathrm{pA}$. Stan detector was used to acquire transmitted electrons through the samples and create high-angle annular dark-field images (HAADF) at higher magnification up to 3,500,000 times. After HAADF image acquisition, $\mathrm{J}$ cut lamella were welded to the micromanipulator of the FIB instrument and pulled out from the sample. Then the lamellae were welded to the $\mathrm{Cu}$ sample holder and stored in a vacuum for TEM/EDS analysis.

\subsection{Transmission electron microscopy \& EDS (TEM-EDS)}

TEM was performed with a JEOL 2100F Transmission electron microscope operating at $200 \mathrm{kV}$, operated in STEM mode with a nominal probe size of $2 \mathrm{~nm}$. The EDX detector was an Oxford $\mathrm{Xmax}^{\mathrm{n}} 80 \mathrm{~T}$.

\subsection{X-ray photoelectron spectroscopy (XPS) etching}

Etching of the inhibited alloy surface were performed by XPS sputtering to reveal the bonding chemistry of different elements at coating-substrate interface. XPS was performed by Kratos AXIS Ultra XPS system (Kratos Analytical Ltd., UK). The spectrometer was equipped with a monochromatic $\mathrm{Al} \mathrm{K} \alpha\left(E_{\text {photon }}=1486.7 \mathrm{eV}\right)$ and an $\mathrm{Ag} \mathrm{L} \alpha$ $\left(E_{\text {photon }}=2984.2 \mathrm{eV}\right) \mathrm{X}$-ray sources. Experimental details have been listed elsewhere [68].

\section{Results}

\subsection{OCP and potentiodynamic polarization scans (PDS)}

OCP measurements are presented in Fig. 2a for uninhibited and inhibited conditions. Uninhibited condition seems to be associated with unstable OCP values with a large fluctuation in voltage. Instability in OCP values could be originated from the uneven distribution of local volta potential across the surface. In the case of uninhibited alloy surface, this could be resulted due to breakdown of the oxide layer, presence of localized cathodes and anodes, or generation of positive and negative ions due to cathodic and anodic partial reaction initiated at IMPs (cathode) and bulk Al (anode), respectively [69]. Inhibited saline solution has contributed to shifting the OCP to more positive values in comparison to blank saline solution. With the increment of exposure time, there was the shift of OCP to more negative values i.e. 7 and 14 days, and the instability of OCP is evident from $10 \mathrm{~min}$ to the rest of the exposure time. There is a shift of OCP from 0.73 to $0.66 \mathrm{~V}$ upon inhibitor addition at 1 day which further dropped down to $0.71 \mathrm{~V}$ and $0.73 \mathrm{~V}$ at 7 and 14 days, respectively.

Corrosion rate of an electrochemical system can be obtained from the PDS curves. Cathodic and anodic polarizations provide the respective corrosion processes occurring in the cathodic and anodic regions of a working electrode [70]. Extrapolation of cathodic and anodic curves in the linear regions to the point of intersection provides both the corrosion potential $\left(E_{\text {corr }}\right)$ and the corrosion current $\left(i_{\text {corr }}\right)$.

Polarization curves for inhibited and uninhibited samples at 1 day, 7 day, and 14 day exposure are presented in Fig. 2b. The quantified parameters from Fig. 2b has been presented in Table 1. Cathodic shifts in the $E_{\text {corr }}$ values can be observed with the addition of the inhibitor for all three time periods $(-0.73 \mathrm{~V}$ to $-0.65 \mathrm{~V},-0.68 \mathrm{~V}$ and $-0.72 \mathrm{~V}$ at time $t=1,7$ and 14 days, respectively). These cathodic shifts suggest that the 2-MBI inhibitor acted as a cathodic inhibitor for the AA6061 system. An $i_{\text {corr }}$ value of $0.035 \mathrm{~mA} \mathrm{~cm}^{-2}$ was observed for uninhibited samples after 1 day. For inhibited conditions, $i_{\text {corr }}$ values decreased to $0.012 \mathrm{~mA} \mathrm{~cm}^{-2}$ after $1 \mathrm{~d}$ and then increased after 7 day and 14 day with corresponding values of $0.022 \mathrm{~mA} \mathrm{~cm}^{-2}$ and $0.028 \mathrm{~mA} \mathrm{~cm}^{-2}$, respectively. An inhibitor efficiency of $64.7 \%$ has been observed in the inhibited condition compared to the uninhibited condition after 1 day. Inhibition efficiency dropped further to $35.7 \%$ and $21.0 \%$ at 7 day and 14 day, respectively. The potential shift towards the cathodic direction in the case of inhibited samples with higher inhibition efficiencies than uninhibited ones implies the resistive properties of 2-MBI and extended coverage of cathodic areas of the working electrode. All these factors could have some influence on the decrease of charge transfer activities across the working electrode surface. Therefore, the possibility of oxygen interaction with the substrate surface is hindered by providing a barrier effect, thus reducing the current flow, i.e. $i_{\text {corr }}$. Reduction of cathodic current in all inhibited exposure time indicates the reduction of cathodic activities due to the presence of inhibitor molecules. In the case uninhibited sample, $E_{\text {corr }}$ was $-0.73 \mathrm{~V}$ initially, shifted toward a positive value for inhibited condition at 1 day, and then decreased again for 7 and 14 day. $i_{\text {corr }}$ exhibits a similar trend to $E_{\text {corr }}$, implying the formation and later breakdown of the passive layers. For the inhibited AA6061, a significantly positively shifted $E_{\text {corr }}$ of $-0.65 \mathrm{~V}$ was obtained, confirming an effective corrosion 
Fig. 2 a Opencircuit potential (OCP), b Potentiodynamic polarization curves of inhibited and uinhibited AA6061 samples pulled out periodically from blank and inhibitor added saline solution at 1 day, 7 days and 14 days then exposed to $0.1 \mathrm{M}$ blank $\mathrm{NaCl}$ solution for $\mathrm{OCP}$ and PDS measurements

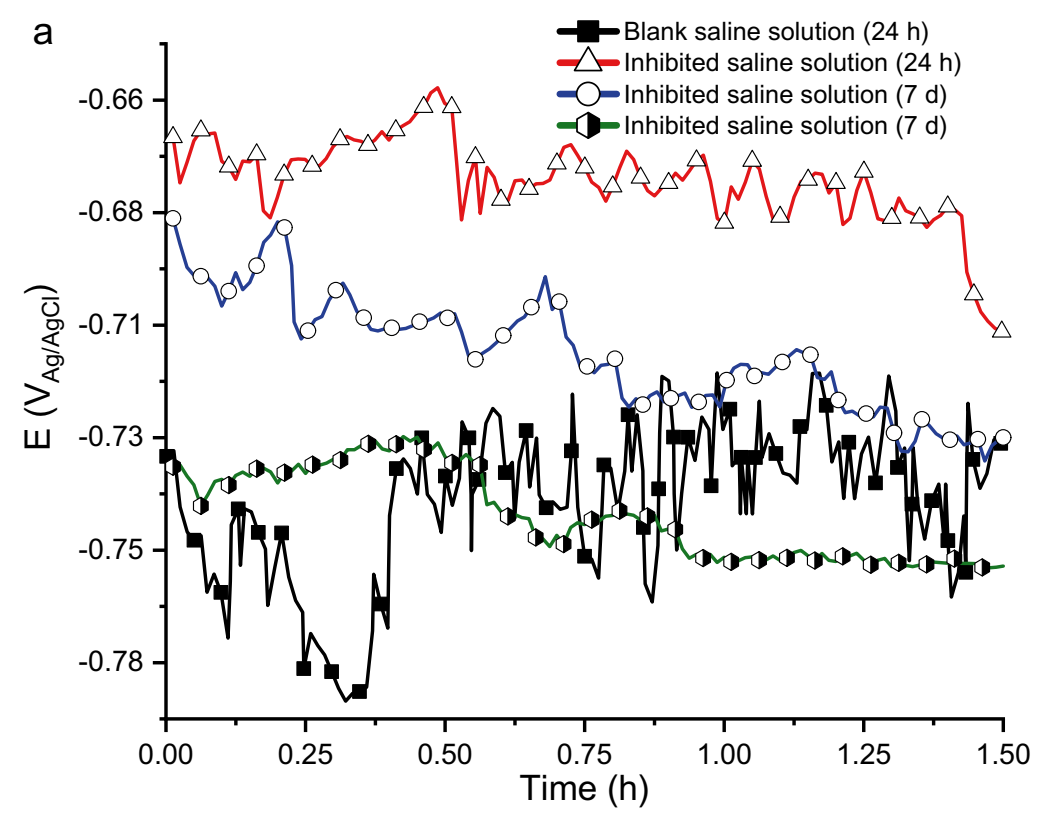

b

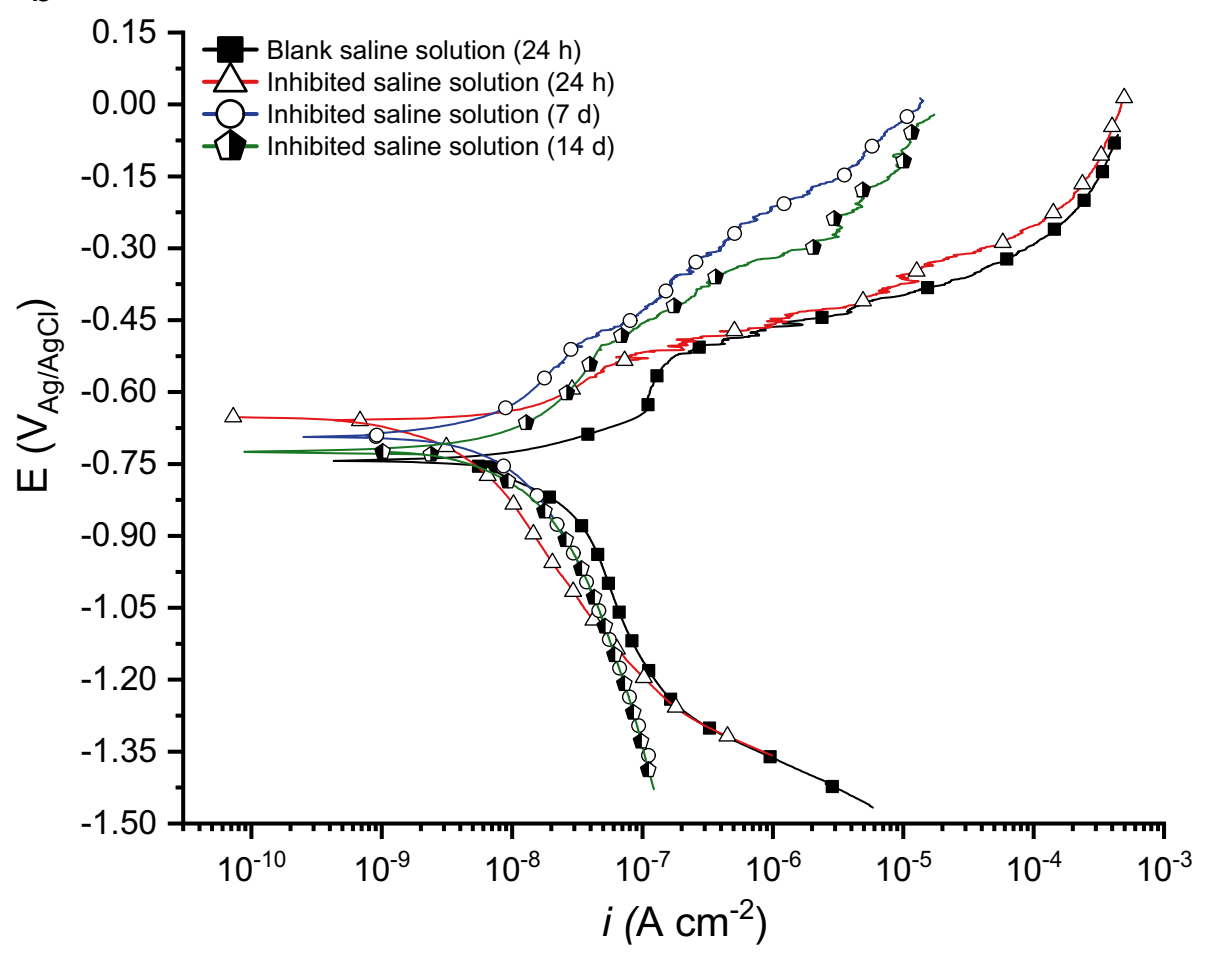

Table 1 Corrosion parameters calculated from EC-Lab software for Fig. 2a

\begin{tabular}{lllll}
\hline Sample conditions & $i_{\text {corr }}\left(\mathrm{mA} \mathrm{cm}^{-2}\right)$ & $E_{\text {corr }}\left(\mathrm{V}_{\mathrm{Ag} / \mathrm{AgCl}}\right)$ & $\begin{array}{l}\text { Anodic Tafel slope, } \\
\beta_{\mathrm{a}}\left(\mathrm{mV} \mathrm{dec}^{-1}\right)\end{array}$ & $\begin{array}{l}\text { Cathodic Tafel } \\
\text { slope, } \beta_{\mathrm{c}}(\mathrm{mV} \\
\left.\mathrm{dec}^{-1}\right)\end{array}$ \\
\hline Uninhibited 1 day & 0.035 & -0.73 & 94 & 85 \\
Inhibited 1 day & 0.012 & -0.65 & 65 & 78 \\
Inhibited 7 day & 0.022 & -0.68 & 72 & 91 \\
Inhibited 14 day & 0.028 & -0.72 & 86 & 92 \\
\hline
\end{tabular}


protection by 2 -MBI. The $E_{\text {corr }}$ gradually decreased over a long immersion time from 7 to 14 days, indicating the good stability of the 2-MBI-induced protection in a $\mathrm{NaCl}$ environment.

Further analysis of the cathodic and anodic regions of the curves reveals a decrease in the cathodic Tafel slopes after 7 and 14 days exposure for inhibited samples. Likewise, a reduction in the voltage range of the anodic passive regions for inhibited samples can be observed after 1 day immersion. However, $E_{\mathrm{corr}}$ values were shifted negatively in anodic regions from $-0.68 \mathrm{~V}$ ( 7 day) to $-0.72 \mathrm{~V}$ after 14 days in the inhibited sample. This could be due to the unstable corrosion products that temporarily shielded the anodic sites of the working electrode that shifted $E_{\text {corr }}$ by $0.07 \mathrm{~V}$. The uninhibited sample showed a passive region in the anodic portion extending from -0.7 to $-0.56 \mathrm{~V}$. Identical region was found to be absent in the inhibited sample for the same duration. These regions have slightly reappeared in 7 and 14 days inhibited samples from -0.6 to $-0.55 \mathrm{~V}$. This passive region could indicate repassivation of anodic sites by the corrosion products.

\subsection{Electrochemical impedance spectroscopy (EIS)}

Impedance responses of the uninhibited and the inhibited alloy surface in the form of Nyquist plots, after 1, 7 and 14 days are presented in Fig. 3a. The corresponding Nyquist response of the uninhibited sample has been provided inset of Fig. 3a because the impedance $(Z)$ values were minimal compared to the inhibited ones. This will help the reader have a quantitative comparison between inhibited and uninhibited samples at longer exposure times.

A metal surface covered with a homogenous coating ideally shows a high impedance in accordance with a simplified Randle's cell. It will possess a single semicircle in the Nyquist plot i.e. a single time constant where the capacitance of the defect-free coating will merge with the inherent metal oxide layer [71]. In that case, the coating and the oxide layer cannot be distinguished by different capacitive elements. However, if the protective layer/coating on the metal surface becomes inhomogeneous and defective, there could be two or more-time constants associated with distinguished semicircles instead of one [72, 73].

In an inhomogeneous or defective coating system, semicircles at higher frequency regions are supposed to be absent or depressed. The absence of higher frequency time constants is attributed to a defective coating system where corrosion was mostly occurring under charge transfer control processes [74]. In a porous and defective coating system, resistance associated with pores $\left(R_{\text {pore }}\right)$ dictates the time constant at higher frequency regions i.e. high-frequency time constants. A coating system is assumed to be less defective at the initial stages of corrosion processes, showcasing a higher $R_{\text {pore }}$ i.e. a time constant in high-frequency regions [75]. With the advancement of time, pores could be generated in the coating structure that facilitates the movement of aggressive ions to the coating-metal interface. Then the Nyquist response results in depressed semicircles with low or medium frequency time constant as the pore resistance decreases. Eventually, it may cause the disappearance of the coating response in the high-frequency region, and the corrosion process could only be controlled by charge transfer processes [72, 75-77].

Nyquist plots displayed in Fig. 3a have shown that the AA6061 samples have a flawed or defective coating layer with a porous structure of inhibited and uninhibited conditions [76]. It has been presumed that AA6061 substrate, i.e. working electrode, is covered with inhibitor-oxide layer/ film. It could be comprised of two separate interfaces: metalcoating interface and coating-electrolyte interface. Thus, two semicircles in the Nyquist plots refer to two different responses of the working electrode. The high-frequency semicircle refers to the coating response which is associated with coating capacitance $\left(Q_{\text {oxide/inhibitor }}\right)$ and pore resistance $\left(R_{\text {pore }}\right)$. The low-frequency semicircle refers to corrosion processes, i.e. charge transfer resistance $\left(R_{\text {charge-transfer }}\right)$ and double-layer capacitance $\left(Q_{\text {double layer }}\right)$ [77]. The total resistance of the electrochemical systems in Fig. 3 a can be described in terms of polarization resistance $R$ pol, a summation of all the resistive elements principally act in a faraday cage $\left(R_{\text {pol }}=R_{\text {pore }}+R_{\text {charge-tranfer }}+R_{\text {solution }}\right)$ [75].

Exposure of AA6061 to the inhibited 2-MBI electrolyte for 1 day, results in a significant rise in $R_{\mathrm{pol}}$ (polarization resistance) as evidenced by the increased diameter of the semicircle compared to the uninhibited sample (inset of Fig. 3a). It underlines the excellent intrinsic inhibitive properties of 2-MBI, i.e. presence of a protective layer [78]. Uninhibited sample found to be associated with depressed semicircles in Nyquist plots, indicating large drop in $R_{\mathrm{pol}}$ values. $R_{\mathrm{pol}}$ value is roughly 22 times lower than those observed for inhibited samples at 1 day (Table 2). Uninhibited samples were observed with more depressed semicircles showcasing lower $R_{\mathrm{pol}}$ values at 7 and 14 days. It confirms either the absence of a barrier layer or a defective oxide layer. Inhibited samples show a reduction in loop diameters with exposure time, which corresponds to a gradual decrease in $R_{\mathrm{pol}}$ values at 7 days and 14 days inhibited sample.

Bode plots are presented in Fig. 3b for different exposure time durations. 2-MBI treated samples show improved low-frequency impedance modulus (IZl) for all exposure times compared to uninhibited ones. IZl gradually drops from $\approx 10^{6}$ to $\approx 2.4 \times 10^{5} \Omega$ for 1 day to 7 days exposure, respectively, for the inhibited conditions. Bode impedance modules further dropped marginally for 14 days inhibited sample to approx. $2.2 \times 10^{5} \Omega$. The same has been calculated as $1.2 \times 10^{5} \Omega$ for uninhibited samples after 1 day. 

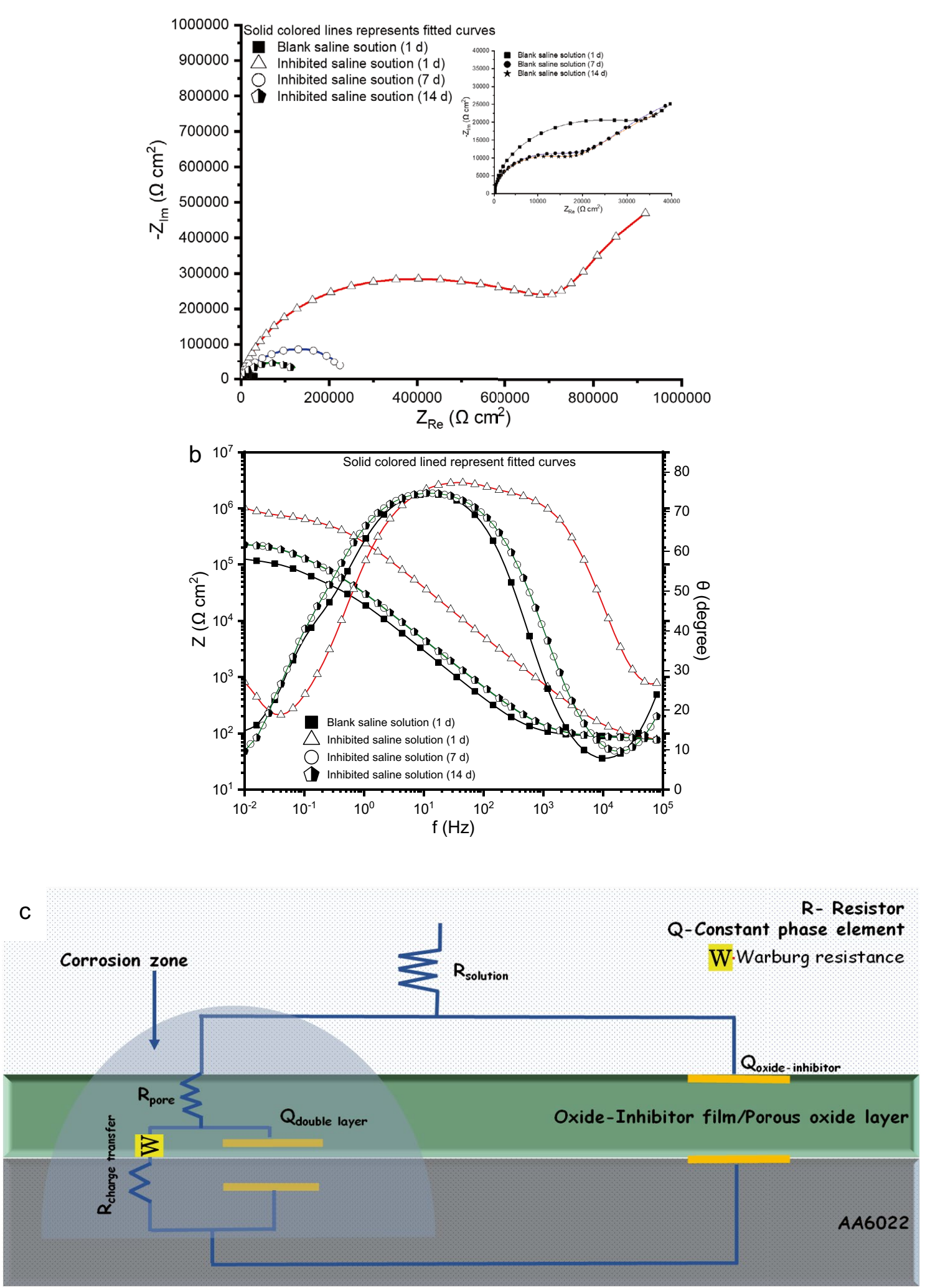

Fig. 3 Results of EIS i.e. a Nyquist plots (Fitted curves are presented in solid black lines), b Bode impedance, $\mathbf{c}$ Bode phase angle d EEC of AA6061 samples pulled out periodically from blank and inhibitor added saline solution at 1 day, 7 days and 14 days then exposed to blank $0.1 \mathrm{M} \mathrm{NaCl}$ solution to perform EIS measurements. (Color figure online) 
Table 2 Calculated value of different parameters of the Equivalent electrical circuit (U and I, refer to uninhibited and inhibited system respectively)

\begin{tabular}{llllll}
\hline $\begin{array}{l}\text { Circuit ele- } \\
\text { ments }\end{array}$ & Units & 1 day (U) & 1 day (I) & 7 day (I) & 14 day (I) \\
\hline$R_{\text {solution }}$ & $\Omega \mathrm{cm}^{2}$ & 244.2 & 694.7 & 550.1 & 98.7 \\
$R_{\text {pore }}$ & $\Omega \mathrm{cm}^{2}$ & $1.5 \times 10^{6}$ & $7.0 \times 10^{6}$ & $5.6 \times 10^{6}$ & $5.5 \times 10^{6}$ \\
$R_{\text {charge-transfer }}$ & $\Omega \mathrm{cm}^{2}$ & 28,205 & 943,922 & 31,655 & 26,025 \\
$Q_{\text {oxide-inhbitor }}$ & $\mathrm{F}$ & $0.67 \times 10^{3}$ & $11.5 \times 10^{6}$ & $0.4 \times 10^{6}$ & $8.5 \times 10^{6}$ \\
$Q_{\text {double layer }}$ & $\mathrm{F}$ & $14.5 \times 10^{6}$ & $0.9 \times 10^{6}$ & $8.5 \times 10^{6}$ & $16.2 \times 10^{6}$ \\
$\eta_{\text {oxide-inhbitor }}$ & & 0.84 & 0.9 & 0.92 & 0.90 \\
$\eta_{\text {double layer }}$ & & 0.94 & 0.9 & 0.97 & 0.86 \\
$W_{\mathrm{s}}$ & $\Omega \mathrm{s}^{-1 / 2}$ & $2.8 \times 10^{6}$ & 9343 & 111,047 & 56,639 \\
\hline
\end{tabular}

The medium frequency modulus is thought to be associated with the diffusion of different ions through the surface films over a metal substrate. Hence, $\theta_{\max }$ (medium frequency phase angle maximum) is considered one of the quantitative indicators of the barrier properties of a protective layer that has formed to the ingress of corrosive species [79]. Bode phase angle plots (Fig. 3b) show the $\left(\theta_{\max }\right)$ for 2-MBI treated samples are typically around $77.5^{\circ}, 75^{\circ}$ and $74.9^{\circ}$ for 1,7 , 14 days exposure periods, respectively (Fig. 3b). $\theta_{\max }$ for the uninhibited condition is found to be $74.8^{\circ}$ for the same exposure period of 1 day, which is nearer to values observed for 7 and 14 days. $\theta_{\max }$ for the uninhibited condition were stable within a narrow frequency range $(7$ to $14 \mathrm{~Hz}$ ). In contrast, it is nearly steady over a wider frequency range ( 3.5 to $950 \mathrm{~Hz}$ ) for the inhibited samples immersed for 1 day. With the momentum of exposure time, a gradual leftward shift of the phase angle vs. frequency plots of the inhibited system with lower $\theta_{\max }$ values is evident from the Bode phase angle plots (Fig. 3b).

Time constants are indicators of different electrochemical processes occurring at the substrate surface with or without coating. An electrochemical system's middle and highfrequency time constants correspond to the electrochemical activities of any coating or coverage present over the substrate. The time constants in the low-frequency range correspond to electrochemical activity at the alloy surface, respectively [1]. In this study, both uninhibited and inhibited samples are thought to have mixed surface coverings produced from oxide layer and inhibitor-induced protective layer, respectively. Therefore, the electrical equivalent circuit (EEC) is fitted with two time constant (Fig. 1d), and Warburg resistance is introduced, to represent ionic diffusion through both the oxide layer and the inhibitor-induced layer [47]. All the circuit parameters are defined with the respective abbreviation in Fig. $3 c$, and the calculated values are presented in Table 2. The constant phase elements (CPE) were used in the EECs to describe the elements as non-ideal capacitors using parameters $Q$ and $\eta$ [80]. The

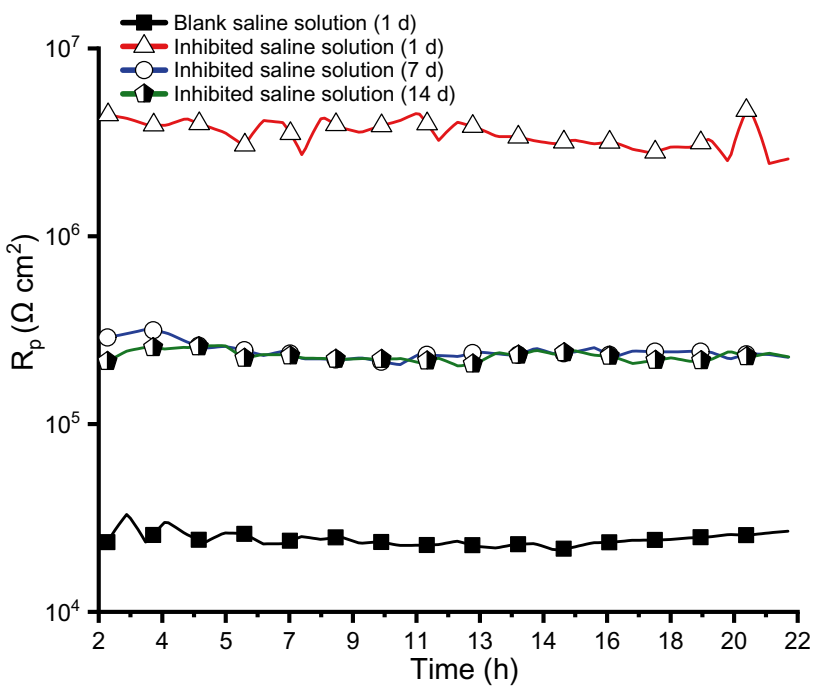

Fig. 4 Polarization resistance $\left(R_{\mathrm{pol}}\right)$ up to $22 \mathrm{~h}$ of different AA6061 samples pulled out periodically from blank and inhibitor added saline solution at 1 day, 7 day and 14 day then exposed to blank $0.1 \mathrm{M} \mathrm{NaCl}$ solution for cyclic polariaztion resistance measurements

inhibited system has an additional second time constant describing the electrochemical processes (corrosion) occurring at the aluminium substrate in terms of the pore resistance $R_{\text {pore }}$ (Fig. 3d). $R_{\text {pore }}$ is the resistance associated with ion-conducting paths that develops in a defective coating that stays on the metal side due to coating degradation [1]. The total value of $R_{\text {pol }}$ can be calculated from the summation of $R_{\text {charge-transfer }}, R_{\text {pore, }}$ and $R_{\text {soultion. }} . R_{\text {pol }}$ values were 13 times higher for the inhibited conditions compared to the uninhibited conditions after 1 day.

\subsection{Linear polarization resistance (LPR)}

Figure 4 shows the polarization resistance $\left(R_{\mathrm{pol}}\right)$ of the AA6061 aluminum alloy for both uninhibited and inhibited conditions at different exposure times. Polarization resistance data with error bars have been presented in Fig. $\mathrm{S} 1$ of the supplementary material. The main difference in the results is that the uninhibited system falls into range $\approx$ $3.0 \times 10^{4}$ to $1.7 \times 10^{4} \Omega \mathrm{cm}^{2}$. In contrast, the inhibited range is much higher, typically between $\approx 3.1 \times 10^{6}$ to $4.2 \times 10^{6}$ $\Omega \mathrm{cm}^{2}$ after 1 day immersion. For the inhibited system, the $R_{\mathrm{pol}}$ values were observed to decrease at 7 days with a range of $\approx 3.1 \times 10^{5}$ to $2.5 \times 10^{5} \Omega \mathrm{cm}^{2}$ and then further slightly dropped within the range of $\approx 2.6 \times 10^{5}$ to $2.0 \times 10^{5} \Omega \mathrm{cm}^{2}$ after 14 days. Polarization resistance values from LPR and EIS equivalent circuit measurements are in accord with each other. Inhibited system display remarkably higher $R_{\mathrm{pol}}$ values compared to the uninhibited system for the 1 day, although the drastic reductions was observed for the inhibited system at 7 days and 14 days. Higher $R_{\text {pol }}$ values attributed to the 
presence of barrier/coating layer over AA6061 in the presence of 2-MBI that gradually dropped with immersion time.

$R_{\text {pol }}$ values can correspond to $i_{\text {corr }}$ values, therefore higher $R_{\mathrm{pol}}$ indicates lower $i_{\text {corr }}$ values. It is suggested that lowering $R_{\mathrm{pol}}$, and hence higher $i_{\text {corr }}$ for the inhibited system with time, can indicate pores or defects in inhibitor-induced protective layer. These results revealed that inhibitor-induced coating/film provided an effective charge transfer barrier that has reduced over time. It is also evident from the drop of $R_{\text {charge-transfer }}$ values in the inhibited condition from 943,922 to $31,655 \Omega \mathrm{cm}^{2}$ and $26,025 \Omega \mathrm{cm}^{2}$ after 7 days and 14 days respectively (Table 2). Diffusion of ions through inhomogeneous inhibitor-induced layer/coating could be one possible reason associated with this gradual drop of $R_{\mathrm{pol}}$ [81]. Alterations of $R_{\text {pol }}$ values could provide valuable information about the long-term durability of an inhibitor-induced protective layer regarding barrier to oxygen reduction and hydrogen evolution reactions occurring on a metal surface. An identical methodology was reported by Hernadez-Alvarado et al. to study the film stability of a chromate-free corrosion inhibitor on steel for a duration of 140 days [82].

After 7 days, the inhibited sample displayed $i_{\text {corr }}$ value of $0.022 \mathrm{~mA} \mathrm{~cm}^{-2}$ compared with $0.012 \mathrm{~mA} \mathrm{~cm}^{-2}$ at 1 day, which further drops to $0.028 \mathrm{~mA} \mathrm{~cm}^{-2}$ after 14 days. These findings accord with the $R_{\mathrm{pol}}$ findings as a reduction in $R_{\mathrm{pol}}$ remain almost identical for both 7 , and 14 days inhibited sample. Lower $i_{\text {corr }}$ values and the positive shifts of $E_{\text {corr }}$ in the cathodic portion suggest that the inhibitor has a dominant effect on the cathodic part of the polarization curve compared to the anodic part. It can be assumed that the cathodic sites could be obstructed to a greater extent by the inhibitor molecules than the anodic sites [83].

\section{$3.4 \mathrm{pH}$ measurements}

Changes in the $\mathrm{pH}$ values with exposure time for both uninhibited and inhibited conditions are presented in Fig. 5. The uninhibited system shows a higher $\mathrm{pH}$ value of 6.82 than 6.75 for the inhibited sample with the same exposure time of 1 day. Inhibited system displayed a moderate rise in $\mathrm{pH}$ values from 6.79 to 6.90 over the 7 to 14 days period of exposure.

\subsubsection{FIB-SEM/EDS, TEM/EDS}

A $\mathrm{J}$ cut TEM-lamella prepared from 1 day inhibited sample by FIB-SEM instrument is presented in Fig. 6a. A dark continuous layer is evident in the lamella beneath the Pt layer, which is thought to be the protective inhibitor layer that has acted as a barrier against corrosive degradation of AA6061 surface identified by electrochemical analysis. To gain more insights, high-angle annular dark-field image (HAADF) of the selected area (red dotted rectangle) from that lamella is

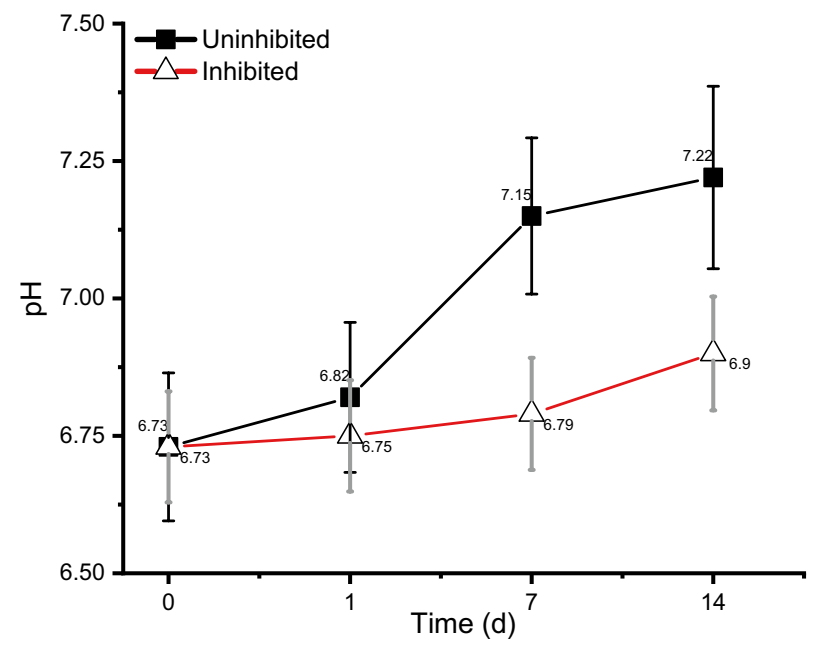

Fig. 5 Changes in $\mathrm{pH}$ values of uninhibited and inhibited electrolyte with time

taken using the Stan detector (Fig. 6b) of FIB instrument. The bright layer consists of several white crystals of aluminum oxide or hydroxides embedded in a grey sponge-like inhomogeneous layer. High-resolution TEM images of the same lamella are presented in Fig. $6 \mathrm{c}$ and $\mathrm{d}$ where the previous bright inhibitor layer has been identified as a continuous grey layer. The white spike-like constituents (blue arrows) are the IMPs distributed heterogeneously across the bulk Al. An EDS line scan of the inhibitor layer (marked by red rectangle) and the IMP beneath that layer (marked by the yellow rectangle) is shown in Fig. 6e and f, respectively. Two principal continents of the 2-MBI are evident from the EDS line scan, i.e. $\mathrm{C}$ and $\mathrm{S}$, along with $\mathrm{Al}$ and $\mathrm{O}$. Here, the $\mathrm{Al}$ signal's intensity is decreased, and the $\mathrm{O}$ signal remains stable over the analysis depth. C and S signals followed an identical signal ratio throughout the analysis depth. It could be attributed to the uniform distribution of inhibitor molecules throughout this layer and indicates the presence of inhibitor molecules (reacted or unreacted) over the aluminum oxide layer.

Among the different nano-sized IMPs identified beneath the inhibitor layer, one has been characterized by EDS line spectra nearest to the outermost surface (yellow dotted rectangle in Fig. 6d). The principal constituent of the IMP is found to be Fe, $\mathrm{Si}, \mathrm{Mn}$, and $\mathrm{Al}$. This phase is thought to be the precipitates of $\beta-\mathrm{Mg} 2 \mathrm{Si}$ or coarse constituent $\alpha$-AlFeMnSi characteristic of $\mathrm{Cu}$-free age hardenable AA6xxx alloys. Age hardenable AA6xxx consists of several types of IMPs, namely, coarse constituent $\alpha-\mathrm{AlFeMnSi}$, pure Si particles, and stable/metastable precipitates of $\beta$-phase $\left(\mathrm{Mg}_{2} \mathrm{Si}\right)$, Q-phase $\left(\mathrm{Al}_{5} \mathrm{Cu}_{2} \mathrm{Mg}_{8} \mathrm{Si}_{6}\right), \theta$-phase $\left(\mathrm{Al}_{2} \mathrm{Cu}\right)$, and $\mathrm{S}$-phase $\left(\mathrm{Al}_{2} \mathrm{CuMg}\right)$ [84]. Fe containing particles could originate from impurities in 6xxx series $\mathrm{Al}$ alloys and its possible phases could be $\mathrm{Al}_{15} \mathrm{FeMn}_{3} \mathrm{Si}_{2}, \mathrm{Al}_{15} \mathrm{FeMn}_{3} \mathrm{Si}_{2}$, and 
Fig. 6 TEM \& FIB-SEM

images of sample immersed

in inhibited saline solution for

1 day: a FIB milled TEM-

lamella, $\mathbf{b}$ magnified view of

inhibitor layer after 1 day, $\mathbf{c}$

high-resolution TEM image of

(b, d) magnified image of yel-

low rectangle form $(\mathbf{c})$. e EDS

line spectra of (d) (red dotted

rectangle), f EDS line spectra

of (d) (yellow dotted rectangle).

(Color figure online)
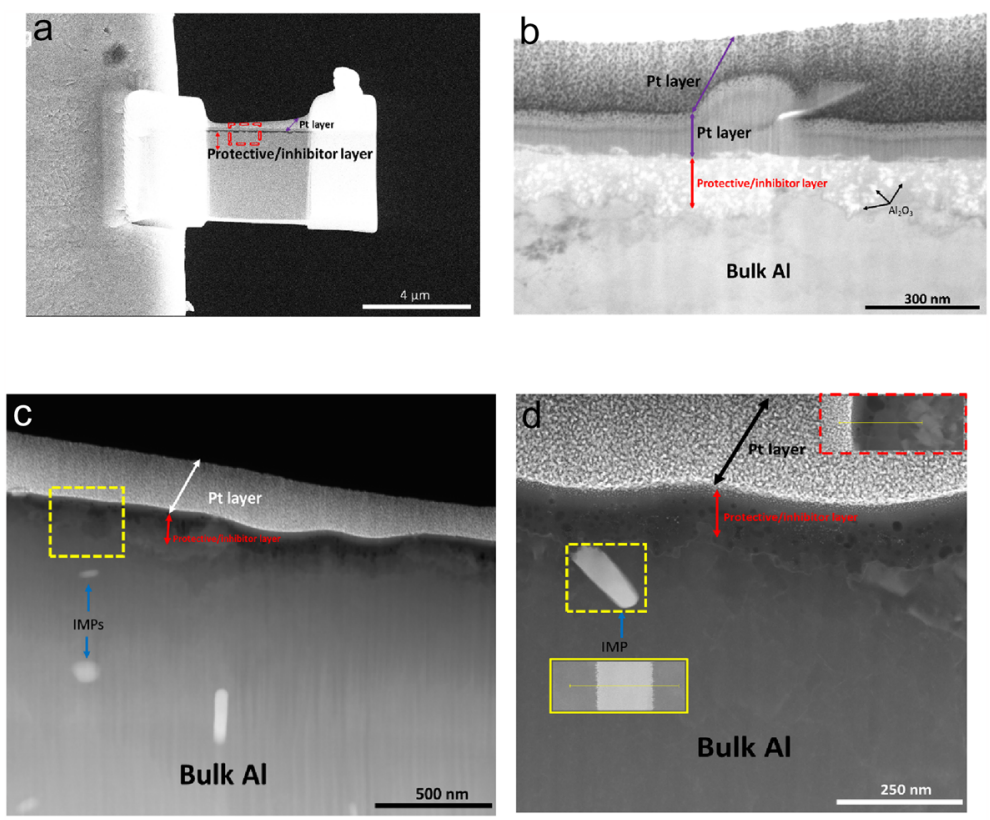

e
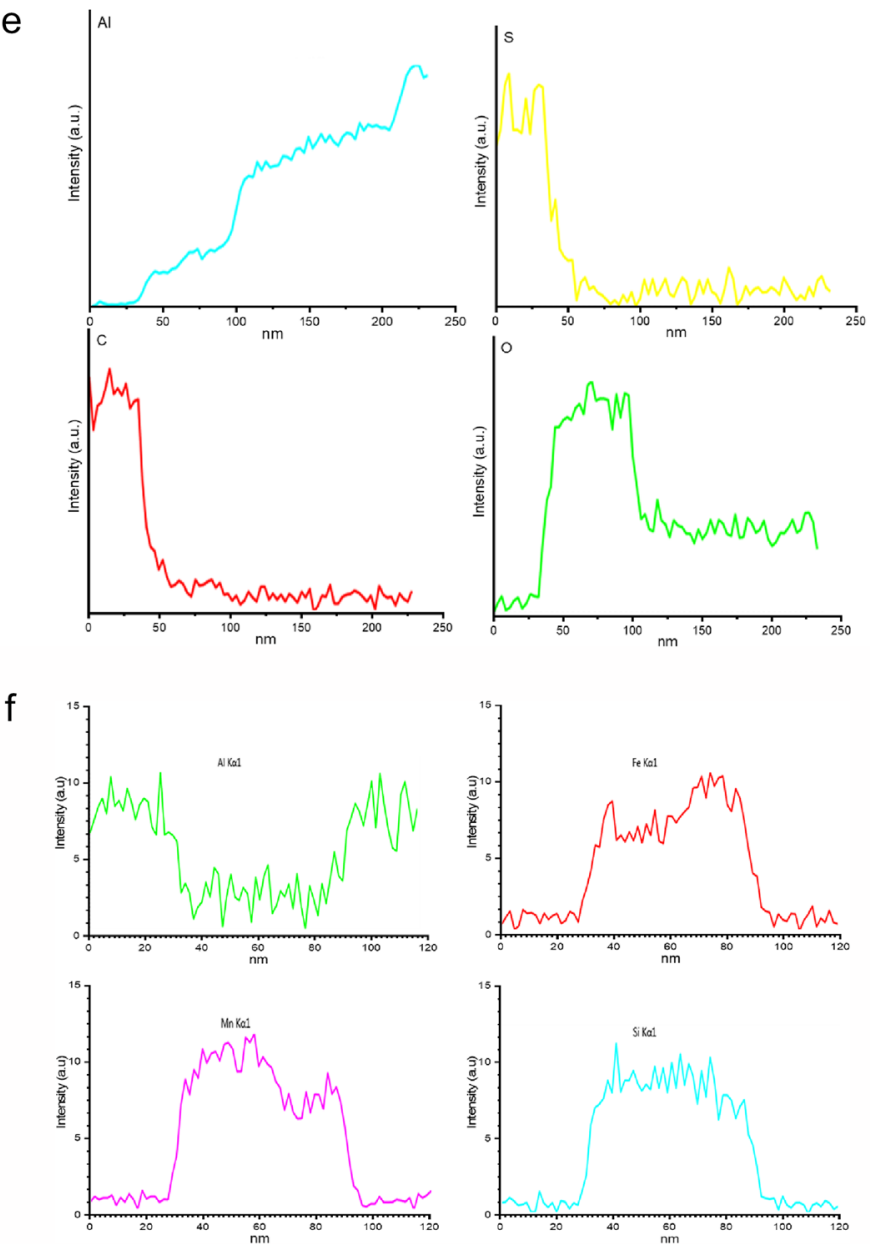

$\mathrm{Al}_{6} \mathrm{FeMn}$. All these IMPs are cathodic with respect to the surrounding $\mathrm{Al}$ matrix and can initiate pitting in the adjacent 
matrix $[85,86]$. However, the identification of the exact composition of this IMP is beyond the scope of this article. Notably, there was no evidence of selective dissolution of $\mathrm{Al}$ in the boundary region. The subsequent enrichment of $\mathrm{Si}$ or Fe seemed to be absent in the identified IMP. Our recent study has revealed that AA6xxx exposed to blank $0.1 \mathrm{M} \mathrm{NaCl}$ solution has suffered selective dissolution of $\mathrm{Al}$ in Fe and Si-rich IMPs at boundary regions and consequent enrichment of nobler constituents [16]. Therefore, the barrier layer produced in the presence of 2-MBI after 1 day has provided adequate coverage to reduce the nano galvanic activity of nobler IMPs to Al matrix and stopped the dissolution of $\mathrm{Al}$ [87].

FIB-SEM image of the inhibited AA6061 specimens after 7 day's exposure is shown in Fig. 7a. The FIB milled cross-section of the same area (Fig. 7b) contains a thick film/layer (20-30 nm) over AA6061. This layer has been detected beneath the Pt deposited layer, and it was not uniform in nature. The composition of this bright layer has been confirmed through EDS map spectra. EDS map spectra of Fig. $7 \mathrm{~b}$ have revealed that this layer consists of S, N, C, with trace amounts of O (Fig. 7c). Al was found to be absent in that thick layer. Beneath that layer, $\mathrm{Si}$ and Fe-rich intermetallic particles were unaffected from corrosion attack. The intactness of Fe and Si-rich IMPs has been assured beneath the thick inhibitor layer due to the absence of porous, sponge-like remnants around the IMPs, which are usually associated with the selective dissolution of $\mathrm{Al}$ or $\mathrm{Mg}$ due to micro galvanic coupling. King and co-workers have observed identical selective dissolution of $\mathrm{Cu}$-rich nobler

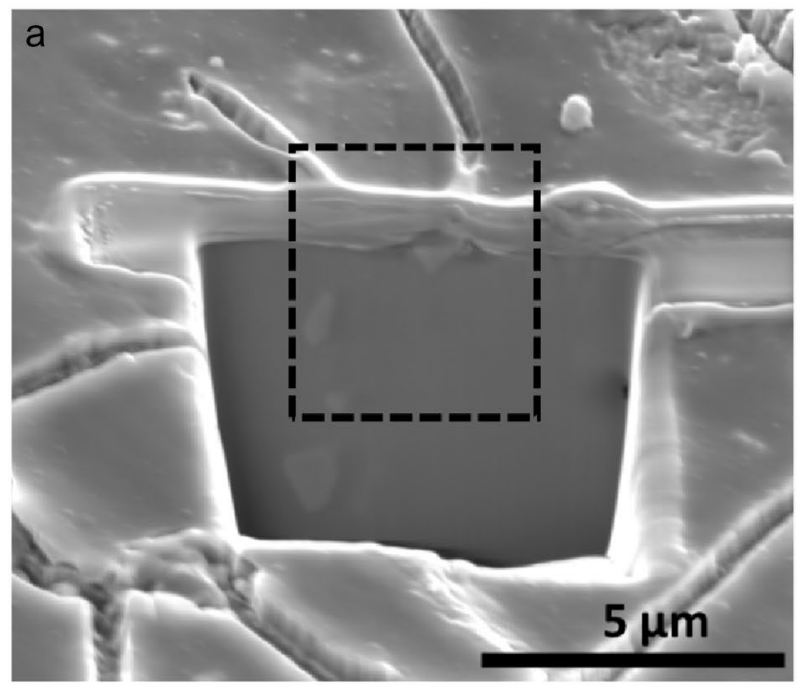

。

Al Kal

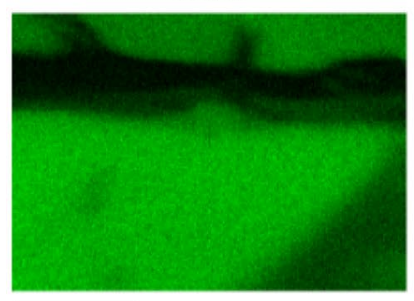

$\stackrel{2.5 \mu \mathrm{m}}{\text { N Kal_2 }}$

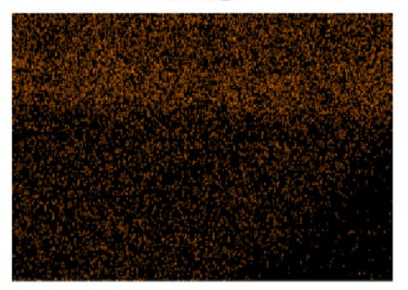

$2.5 \mu \mathrm{m}$
$\mathrm{O} \alpha \mathbf{1}$
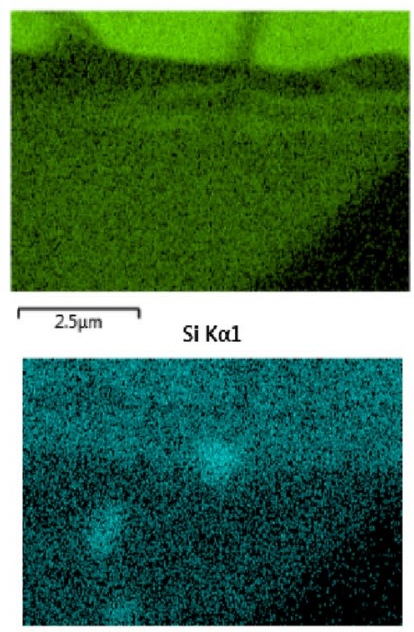

$\longdiv { 2 . 5 \mu \mathrm { m } }$
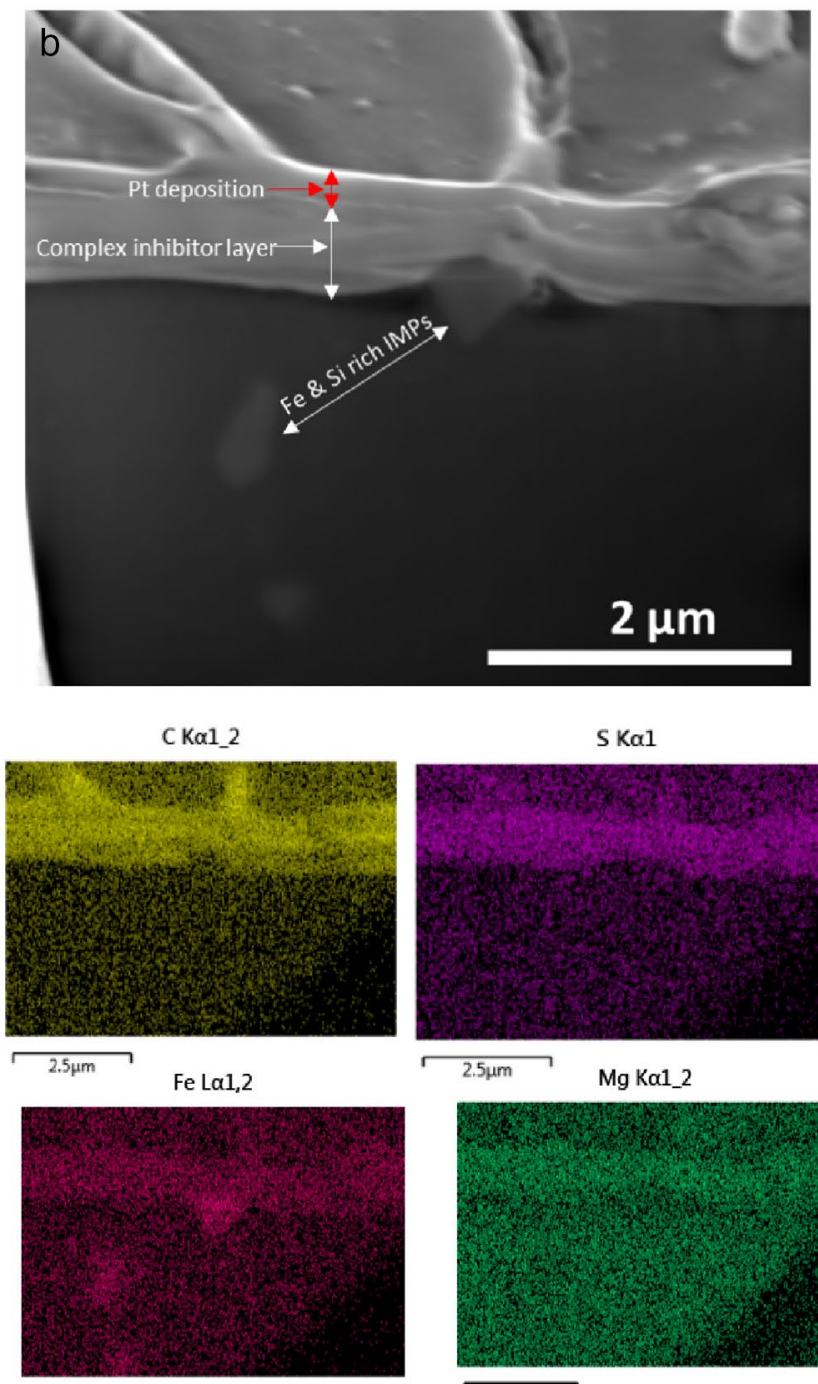

$2.5 \mu \mathrm{m}$
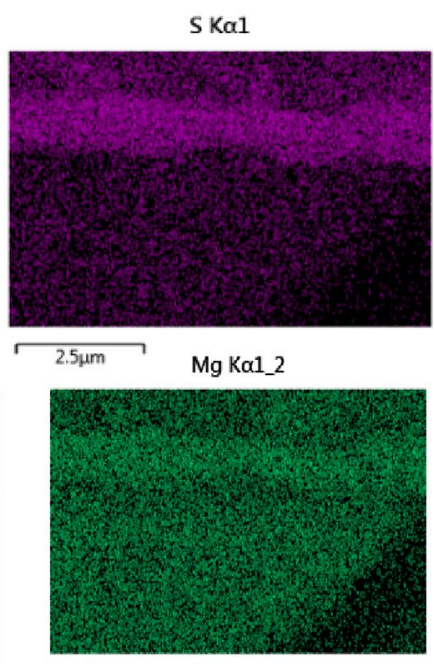

$2.5 \mu \mathrm{m}$

Fig. 7 FIB-SEM images of sample immersed in inhibited saline solution for 7 day a FIB milled section, $\mathbf{b}$ magnified view of black dotted area from a showing inhibitor layer after 7 day, $\mathbf{c}$ EDS map spectra of (b). (Color figure online) 
IMPs of AA2024 exposed to $\mathrm{NaCl}$ droplet [88]. Porous and sponge-like remnants were observed in anodic sites (AA2024 matrix) compared to the cathodic IMPs, which were nobler than the matrix. Dealloying of $\mathrm{Al}$ and $\mathrm{Mg}$ and consequent $\mathrm{Cu}$ enrichment were also reported.
Figure 8 showcases the 2-MBI induced protective layer in 14 days inhibited sample. This layer seems thicker after 14 days immersion compared to 1 and 7 days. The continuity of this layer seemed to be reduced with time, corroborating the electrochemical analysis findings. The discontinuity of this layer may influence ionic transportation to the bulk alloy

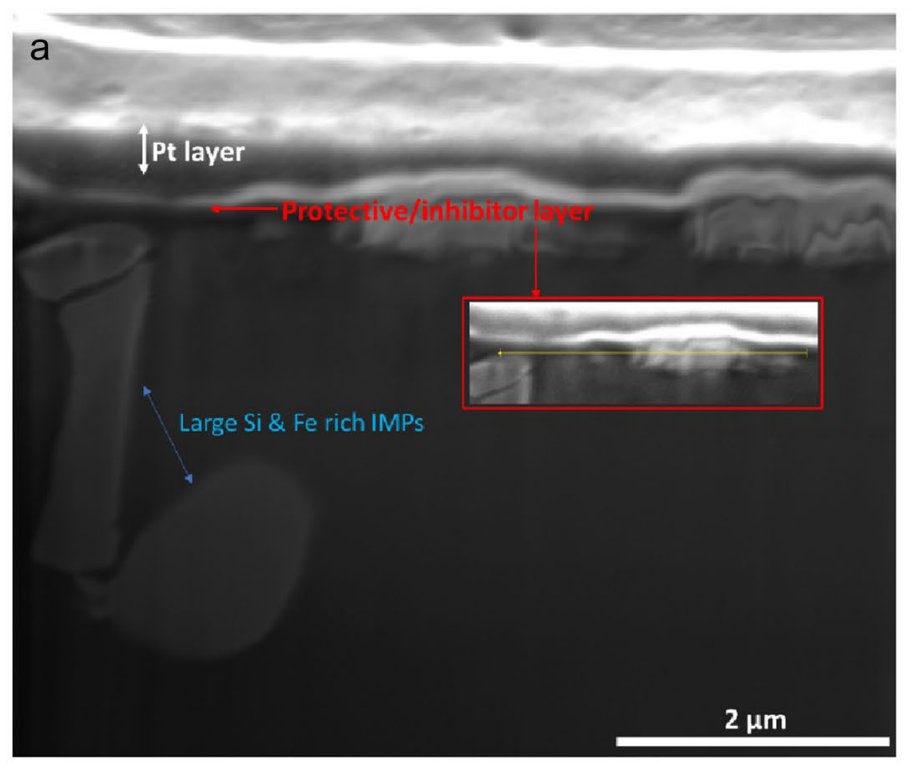

b

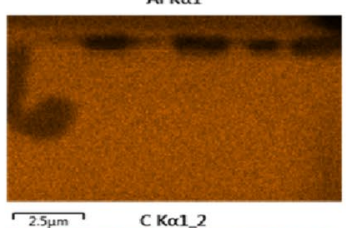

$\sqrt{2.5 \mu \mathrm{m}} \quad \mathrm{CK \alpha 1} 2$

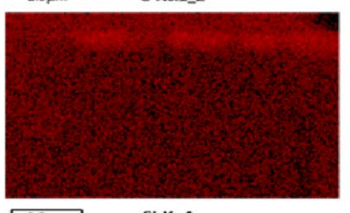

$\sqrt{2.5 \mu m}$ Si Kal

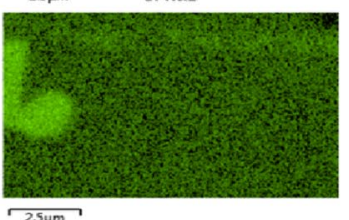

$\longdiv { 2 . 5 \mu \mathrm { m } }$
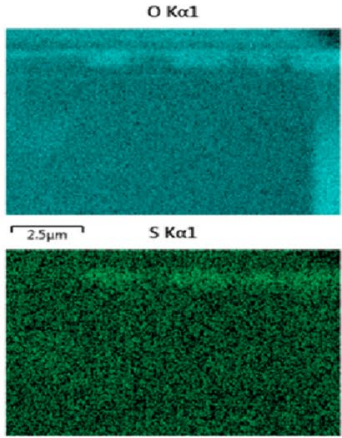

$\sqrt{2.5 \mu \mathrm{m}} \quad \mathrm{Fe} \operatorname{La1}, 2$

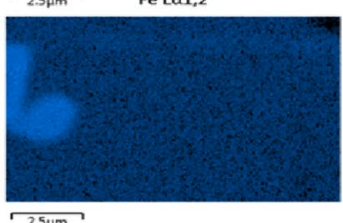

C
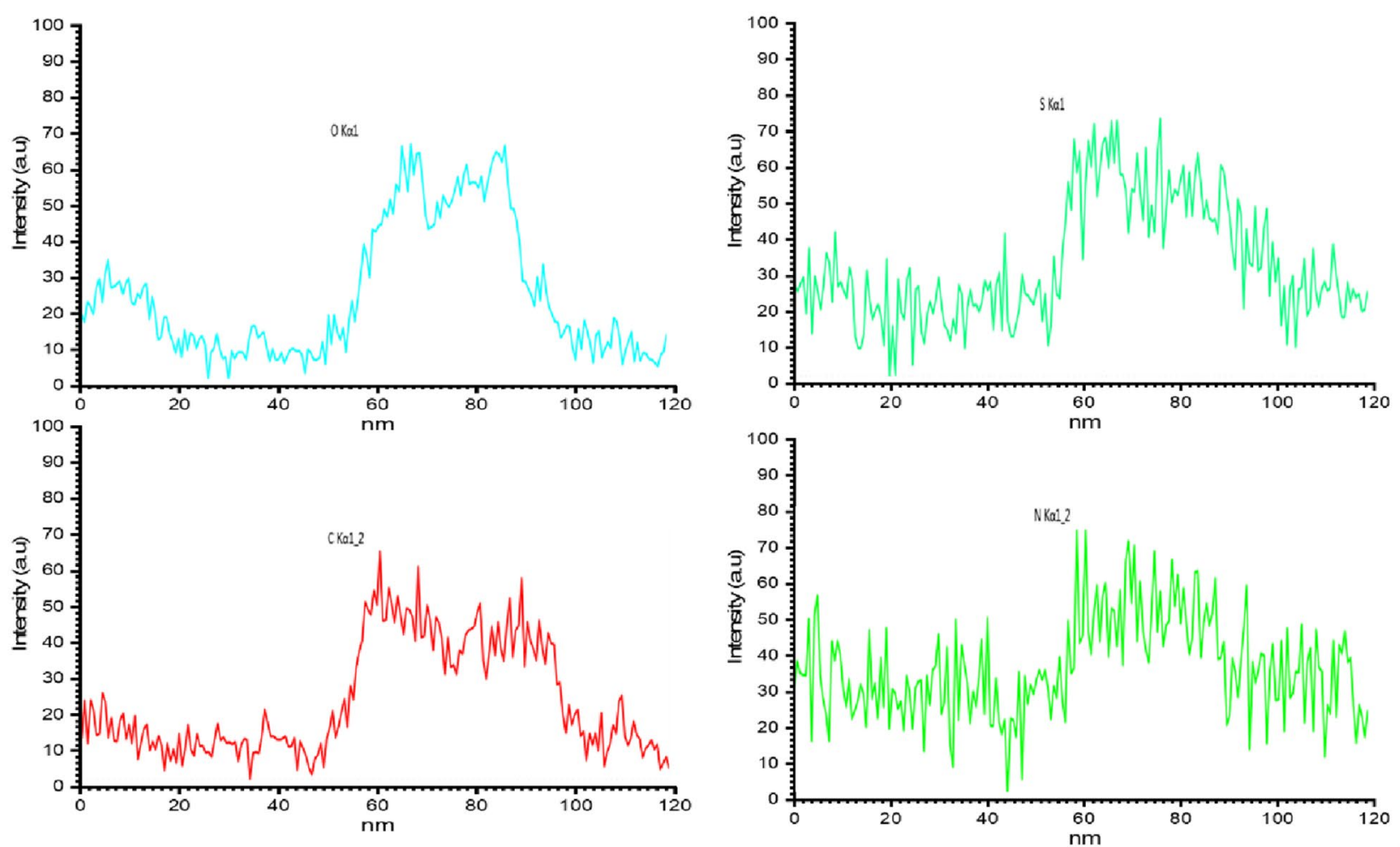

Fig. 8 FIB-SEM images of sample immersed in inhibited saline solution for 14 days a FIB milled section inhibitor layer after 14 days, b EDS mapping of (a), c EDS line spectra of (a) (red rectangle). (Color figure online) 
surface contributing to the reduction of barrier properties against charge transfer processes. However, the protectiveness of this layer against micro galvanic activity was found to be consistent after 14 days. The intactness of micronized $\mathrm{Si}$ and Fe-rich IMP beneath the discontinuous 2-MBI layer duly support this finding. The composition of the protective layer revealed the presence of $\mathrm{S}, \mathrm{C}$, and $\mathrm{N}$, which is thought to be originated from the 2-MBI molecules. The increased thickness of the protective layer and the detection of additional $\mathrm{N}$ signals could result from physically absorbed 2-MBI molecules. However, the exact composition of this thickened layer is yet to be explored.

\subsection{XPS etching}

XPS wide survey spectra before sputtering has been presented in Fig. 9a. The at\% of $\mathrm{C}$ found to be highest among the other elements that could be referring to pick up adventitious carbon from the environment in addition to inhibitor molecules. Besides $\mathrm{C}, \mathrm{S}$ and $\mathrm{N}$ have been traced with excess $\mathrm{O}$ which could be originated from the oxide layer inherently present over $\mathrm{Al}$ surface. The comparative spectrums of inner most and outer most etched layers have been presented in Fig. S2 of supplementary material. Here, both $\mathrm{Al} 2 \mathrm{~s}$ and $2 \mathrm{p}$ spectra have been considered as they both indicate the identical bonding environments of $\mathrm{Al}$, reducing the ambiguity originating from $\mathrm{Al}$ plasmons.

Sputtering with a gas cluster ion beam (GCIB), the change of $\mathrm{Al} 2 \mathrm{p}$ peak was significant after the first sputtering cycle (Fig. 2a in supplementary material). It shows two prominent peaks of binding energy, $75.64 \mathrm{eV}$ and $72.73 \mathrm{eV}$ for aluminum oxide and metal peaks. The outer most etched layer displays a narrow oxide and a metal peak that gets broader in the inner most layer (Fig. 9b, Ap 2 s). This finding is thought to be related to surface Al's activity increment with available surface elements, i.e. oxygen or 2-MBI, and probable formation of $\mathrm{Al}-2 \mathrm{MBI}$ complex. The latter stages of etching might indicate the partial removal of the Al-2MBI complex from the surface, producing more signals for the $\mathrm{Al}_{2} \mathrm{O}_{3}$ and $\mathrm{Al}$ underneath the organic inhibitor layer. From the oxide metal peak ratio, the calculated oxide layer thickness was found to be approximately $3.3 \mathrm{~nm}$. Oxide layer thickness has been calculated using the following equation reported elsewhere [89]. Here, $d$ is the oxide thickness in angstrom. $I_{\mathrm{m}}$ and $I_{0}$, are the intensities (i.e. peak areas) of the metal and oxide photoelectron peaks, respectively.

This layer could be the thickness of the Al-2MBI complex, which is much higher than the perpendicular length of 2-MBI in monolayer orientation. These results indicate having both chemisorbed and physio-absorbed 2-MBI molecules on AA6061.
$d(A)=28 \ln \left(1.4 I_{0} / I_{m}+1\right)$.

The dominant $\mathrm{C} 1 \mathrm{~s}$ peak has been observed at $284.8 \mathrm{eV}$ (Fig. 9c). It has been reported previously that 2-MBI solid chemical (powder), can be associated with three deconvoluted peaks referring to three different carbon environments. Here, the peak position at $284.8 \mathrm{eV}$ (Fig. 9c) corresponds to the four carbon atoms in the benzene ring (not bonded to $\mathrm{N}$ ) and the other two peaks at $286.51 \mathrm{eV} 288.46 \mathrm{eV}$ correspond to the $\mathrm{C}$ atoms bonded to $\mathrm{S}$ and $\mathrm{N}$ atoms, respectively. Studies have revealed that upon adsorption 2-MBI on the metal surface, no peak at $288.46 \mathrm{eV}$ should be observed in the $\mathrm{C}$ $1 \mathrm{~s}$ spectra at all (Fig. 9c) [90-92]. The peak at $288 \mathrm{eV}$ in the $\mathrm{C} 1 \mathrm{~s}$ spectrum corresponds to the carboxylic groups [90, 92-94]. 2-MBI powder with $99 \mathrm{wt} \%$ purity was employed in this study. However, it is possible that it also contained some other oxidized species containing carbon (impurities). Therefore, the peak at $288.46 \mathrm{eV}$ most likely arises due to the presence of oxidized carbonaceous contaminants [12].

The gradual removal of the 2-MBI inhibitor layer by sputter beams shows the possibility of having two $\mathrm{N}$ environments (Fig. 9c). As this was not the case for the outermost layer (Fig. S2b of the supplementary material), it is more likely that these two peaks ( $399.87 \mathrm{eV}$ and $401.02 \mathrm{eV}$ ) correspond to two different 2-MBI molecules bonding. Firstly, the topmost position involves the MBI-organometallic complex (401.02 eV), and secondly, 2-MBI molecules bonded with AA6061 substrate that are not engaged in organometallic complexes (399.87 eV) [95]. These two ways of 2-MBI bonding can already be detected simultaneously after sputtering, as seen in Fig. 9d.

A similar shift of the intensive feature is evident in Fig. 9b from the outermost layer to inner most layer, i.e. position for the $S 2 p$ spectra. The shift of $S 2 \mathrm{~s}$ spectra has been presented in Fig. S2c of supplementary material to distinguish $S$ peaks from Al peaks more precisely as $S 2 p$ spectra could coincide with Al plasmons. These shifts of the $\mathrm{N} 1 \mathrm{~s}$ and $\mathrm{S} 2 \mathrm{~s}$ support the claims of having two different types of 2-MBI bonding on the AA6061 surface. Moreover, the shape of the $S 2 p$ spectra in Fig. $9 b$ matches the $S 2 p_{3 / 2}$ and $\mathrm{S} 2 \mathrm{p}_{1 / 2}$ peaks separated by $1.26 \mathrm{eV}$ with an intensity ratio of $1: 2[13,90,96]$. The main peak 1 for the 2-MBI solid chemical reported to be located at EB of $162.3 \mathrm{eV}$ (Fig. 9b), which agrees with the position of 2-MBI reported previously [97]. The S 2 p peak at $162.80 \mathrm{eV}$ accords with the position for the thiol group, and. Since peaks at higher binding energies were not observed (166-172 eV) in the $\mathrm{S}$ $2 p$ spectra, no $S$ oxidation is thought to have occurred [ 96 , 98-100]. For sulphonates (oxygenated S), a peak at binding energy more positive than $166 \mathrm{eV}$ have been suggested in previous studies [101]. The change of the $\mathrm{S} 2 \mathrm{~s}$ spectrum in the innermost layer for the inhibited AA6061 suggests S-Al 
Fig. 9 a XPS survey spectra before etching, High-resolution XPS spectra of different elements after etching, b Al $2 \mathrm{~s}$ and $\mathrm{S} 2 \mathrm{p}, \mathbf{c} \mathrm{C} 1 \mathrm{~s}, \mathbf{d ~ N} 1 \mathrm{~s}$ from inhibited sample after 1 day a

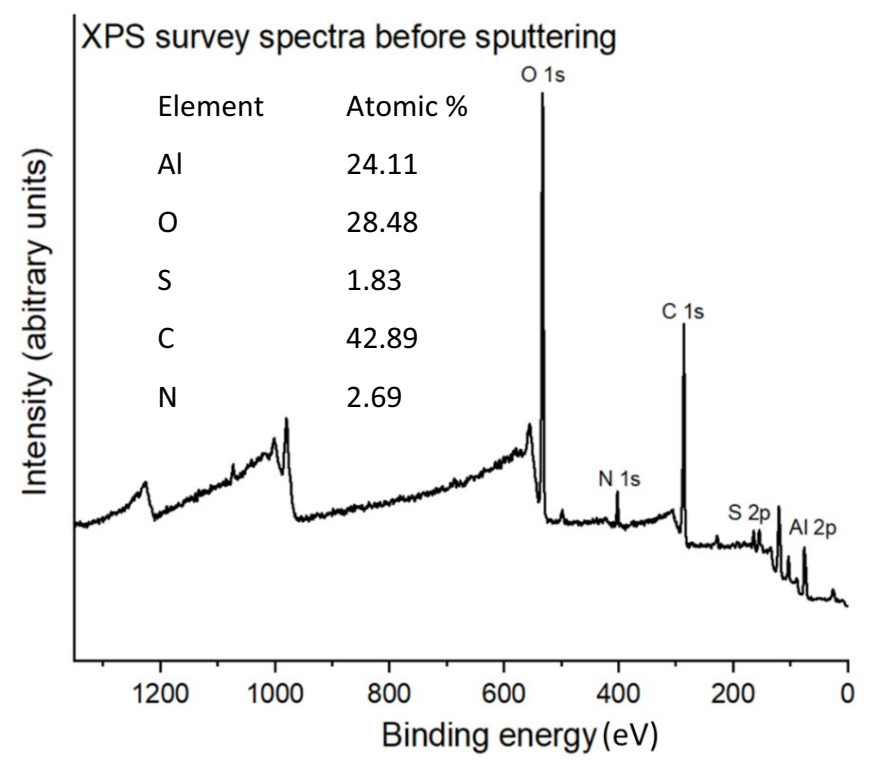

b

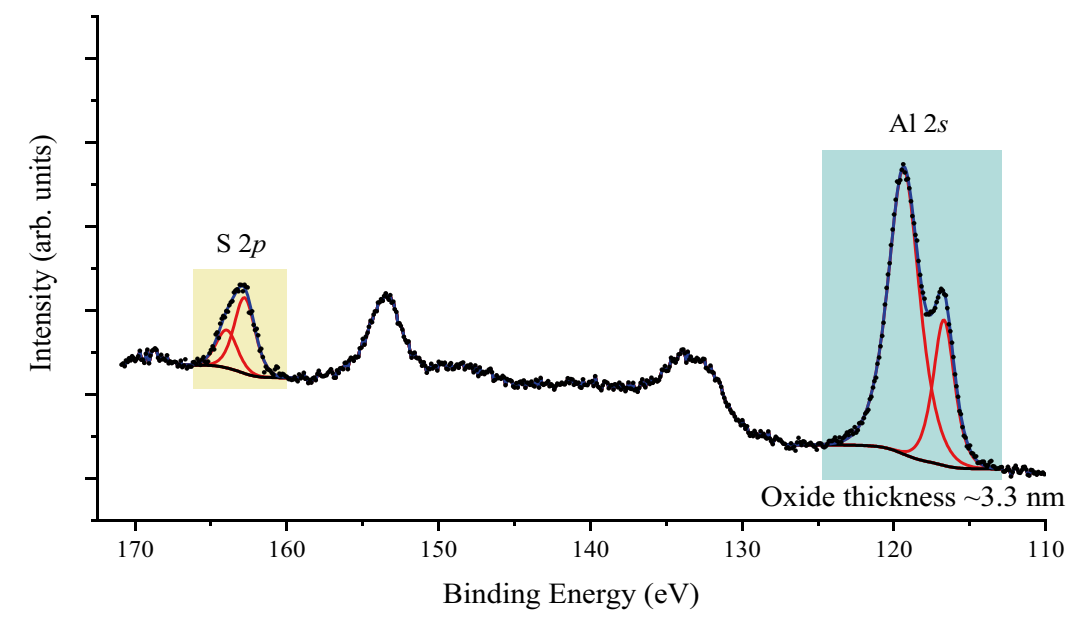

C

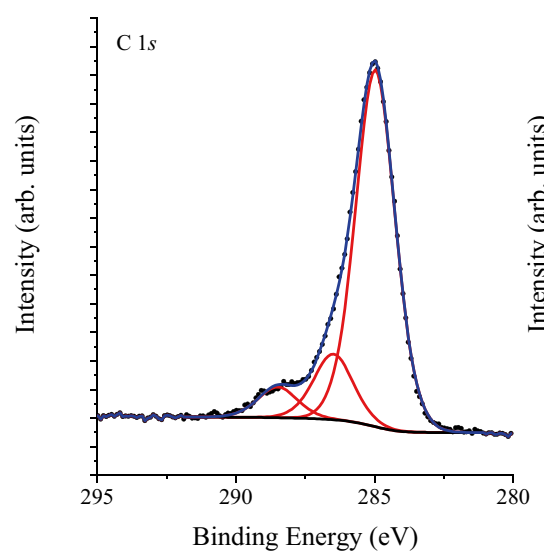

d

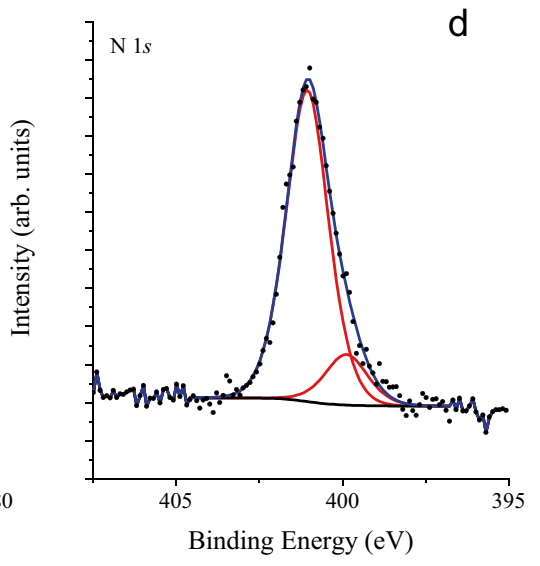

bonding. Different authors have also reported that bonded thiols in the form of thiolate could be located at lower binding energies compared to unbound thiol molecules where the metal ions replace $\mathrm{H}$ from the $\mathrm{S}-\mathrm{H}$ bond $[13,90,102]$.
In this case, 2-MBI treated AA6061 showcased the features of the thiolate bond at binding energy $164.03 \mathrm{eV}$. 


\section{Discussion}

\subsection{Formation of a protective inhibitor layer}

Open circuit potential measurements (OCP) have predicted the presence of a protective layer that has masked the localized cathodes and anodes and shifted the potential to more positive values. This trend is typical for azole-based organic inhibitors that could minimize the localized cathodic and anodic activities [8, 38, 103, 104]. This surface coverage results in a non-homogenous coating layer protecting the bulk against ionic diffusion [44]. The nature of unstable OCPs at longer immersion times could be associated with the nonuniform nature of the inhibitor coverage on AA6061. The Decline to more negative OCPs at 7 day and 14 day could be associated with thicker and porous inhibitor coverage that allows the diffusion of aggressive ions with time [105].

The presence of a protective layer has also been identified from the improved polarization resistance $\left(R_{\mathrm{pol}}\right)$ values observed from Nyquist and Bode plots for the inhibited conditions. Bode impedance plot reveals that low-frequency impedance modulus (/Z/) has increased for the inhibited condition compared to the uninhibited system, mainly attributed to improved corrosion protection through film formation [106]. The improved $R_{\text {pol }}$ values up to 1 day could be associated with rapid formation of a protective layer and consequent adsorption of inhibitor molecules to the substrate surface, which is also identified by polarization resistance values observed in Fig. 4. Prakashaiah et al. [107] observed identical findings for AA2024 with three thiosemicarzone derivatives in $\mathrm{NaCl}$ solution. They correlated the increased $R_{\text {pol }}$ values with the subsequent adsorption of inhibitor molecules to the substrate surface and desorption of water molecules. It is evident from EIS data that the corrosion inhibition provided by 2-MBI on AA6061 remain irreversible up to 1 day. Irreversibility of corrosion inhibition is one of the principle aspects corrosion resistance that is well established for AA2XXX series alloys with different azole derivatives like benzotriazole and 2-mercaptobenzothiazole in saline solutions, unlike AA6XXX [54]. 2-MBI induced inhibitor layer manifests moderate barrier against ionic diffusion in up to 1 day and then degrades gradually up to 14 , which is evident from depressed semicircles of Nyquist plots. This could be attributed to the subsequent ingress of aggressive ions through the inhibitor layer that may produce a more porous and defective layer with the progression of time [108].

\subsection{Structural evaluation of the inhibitor-induced layer from electrochemical measurements}

The inhibited system manifested stable $\theta_{\max }$ values for a wide range of frequencies. Inhibited system was associated with stable $\theta_{\max }$ for a wide range of frequencies postulating slower diffusion tendency of ionic species through a protective coating [48]. The inhibited system predominantly shows a middle-frequency time constant over a wide frequency range. According to Recloux et al. [48], a time constant with a wide frequency spread could not be specific to either the inhibitive layer or oxide film. Instead, the medium or high-frequency relaxation process (widespread $\theta_{\max }$ values) could result from both the oxide and inhibitive layer impedance properties. These studies infer the presence of a complex corrosion protective layer that could be comprised of absorbed inhibitor molecules, an oxide layer, or available surface compounds that result in the improved $R_{\mathrm{pol}}$ values. This symmetry suggests that there are possibly no overlapping time constants in this frequency range. Visser et al. have investigated AA2024 with different inhibitors up to $168 \mathrm{~h}$ and reported that asymmetric phase angle maxima could be due to the presence of two overlapping peaks [1]. It was suggested that this phenomenon referred to a discrete oxide layer beneath the inhibitor layer. Therefore, they have used individual time constants for those overlapping peaks. However, this may not be the case for this study as two well-defined time constants are visible with good symmetry (Fig. 3b). Consequently, the EEC (Fig. 3c) of the inhibited AA6061 is best fitted with two time constants referring to a thick protective layer as observed in the FIB-SEM cross sections.

It is evident from Fig. $3 b$ that after 1 day, the inhibited sample has a high-frequency time constant extended with a shoulder expanded from 1000 to $10,000 \mathrm{~Hz}$. This highfrequency shoulder found to be absent in 7 and 14 day. This could be attributed to the gradual diffusion of aggressive ions through the thick inhibitor layer penetrating with time. Aggressive ions might have diffused to the oxide layer (protected beneath absorbed inhibitor molecules), reaching the alloy surface and facilitating its break down. In later stages, the oxide layer could be partially repaired by the inhibitor layer as the Warburg resistance values were higher at 7 day (Table 2) i.e. better resistance to ionic diffusion. Therefore, after 14 days, the substrate surface had a more complex mixed layer and high-frequency shoulder region of the phase angle curve found to be absent. The absence of a high-frequency shoulder region in the phase angle plot could be associated with low pore resistance. This later process also allows more water and aggressive ions to diffuse through to the surface, altering both $R_{\text {pore }}$ and $R_{\text {charge-transfer }}$ along with the capacitance of both layers. $R_{\text {pore }}$ values were found to decrease from 943,922 to $26,025 \Omega \mathrm{cm}^{2}$ after 14 days 
inhibited sample (Table 2), indicative of time-dependent transportation of aggressive ions thought the pores generated inside the coating structure. These findings postulate the porous nature of the inhibitor film after 14 days with a complex chemical composition comprised of oxides and inhibitor elements.

\subsection{Influence of inhibitor layer on electrochemical parameters and its barrier properties}

Nyquist plots have divulged the better $R_{\mathrm{pol}}\left(R_{\mathrm{pol}}=R_{\mathrm{pore}}+\right.$ $R_{\text {charge-tranfer }}+R_{\text {solution }}$ ) values for the inhibited sample that could be associated with the emergence of 2-MBI induced protective layer or coexistent inhibitor-oxide mixed layer. The nyquist plot could consist of two semicircles in an inhomogeneous coating system. The semicircle at highfrequency is related to the coating response and the lowfrequency semicircle is related to corrosion processes [73]. The equivalent circuit diagram (EEC) presented in Fig. 3c suggests two related effects occurring on the AA6061 surface. Firstly, a coating builds up over AA6061, and secondly, the active metal surface is gradually covered by inhibitor molecules. The coating layer affects the resistive $\left(R_{\text {pore }}\right)$ and a capacitive element $\left(Q_{\text {inhibitor-oxide }}\right)$ which attributes to highfrequency responses of Nyquist plots in the inhibited conditions. Tweaking of $R_{\text {pore }}$ values (Table 2) from $54.8 \times 10^{6}$ $\Omega \mathrm{cm}^{2}$ (uninhibited) to $72.1 \times 10^{6} \Omega \mathrm{cm}^{2}$ (inhibited) confirms the barrier effect of inhibitor layer/film against water adsorption, charge transfer, ingress of aggressive ions. It is also indicative of surface coverage inhibitor molecules after 1 day. However, a drop in $R_{\text {pore }}$ values at 7 and 14 days immersed sample indicates gradual loss in protective nature of the inhibitor-induced film/layer due to either ingress of aggressive ions or adsorption of water molecules through the inhibitor-metal interface or both. Another aspect of protectiveness of an inhibitor-induced layer could be the surface coverage of the inhibitor molecules. This could help retract water molecules and counter-ions, declining the double-layer capacitance $\left(Q_{\mathrm{dl}}\right)$ and concurrently enhancing the charge transfer resistance. With the inhibitor addition, the available surface area for charge transfer activities decreases, and thus $R_{\text {charge-transfer }}$ increases at 1 day and then reduces drastically after 7 days (Table 2). Additionally, after 7 and 14 days the double-layer capacitance $\left(Q_{\mathrm{dl}}\right)$ has increased more than 10 times. The progressive rise in the $\left(Q_{\mathrm{dl}}\right)$ double-layer capacitance values at 7 and 14 days could indicate water adsorption over AA6061 [109, 110].

$R_{\text {charge-transfer }}$ values are a useful indicator for the inhibitor performance that ultimately influence the overall corrosion rate. This could be illustrated by exchanging positive and negative charges during the electron-donation and back-donation from the substrate surface and subsequent substrate diffusion into the corrosive electrolyte. A Higher
$R_{\text {charge-transfer }}$ value is associated with the resistive behavior of the metal, implying the effectiveness inhibitor against charge transfer processes. In addition to that, it could also be an area effect, i.e. the higher active surface area will provide higher $R_{\text {charge-transfer }}$ values. However, the decrease in $R_{\text {charge-transfer }}$ values after 1 day in the inhibited condition might have emerged because of the broadening pores on the inhibitor-induced protective layer that possibly decreased the inhibitor coverage over AA6061. The progressive drop of the $Q_{\mathrm{dl}}$ (double-layer capacitance) in the inhibited sample could be attributed to the adsorption of 2-MBI and subsequent water displacement from AA6061 [109, 110].

The higher $R_{\text {charge-transfer }}$ and lower $Q_{\mathrm{dl}}$ values reveal the stabilizing effect of 2-MBI on the oxide layer on the AA6061 substrate. This behavior indicates the rapid formation of a protective layer on the substrate, followed by gradual densification of this layer with reduced porosity, overall increasing the oxide resistance while maintaining its thickness, as reflected by the FIB-SEM studies. Visser et al. [54] have reported such an identical stabilizing effect of 2-mercaptobenzothiazole on AA2024 substrate, which includes the coverage of $\mathrm{Fe}$ or $\mathrm{Cu}$ rich intermetallic particles and subsequent higher $R_{\text {pol }}$ values being reported. In comparison to uninhibited samples, $R_{\text {charge-transfer }}$ for 2-MBI treated samples increased by a factor of 1.5 times (Table 2). This implies that 2-MBI stabilizes the aluminium oxide up to 1 day, the time period where the highest $R_{\text {charge-transfer }}$ values were observed. A gradual reduction in the $R_{\text {charge-transfer }}$ can be observed upon exposure up to $14 \mathrm{~d}$. Time-dependent desorption of the inhibitor molecules from the substrate surface, due to the presence of a porous and defective complex inhibitor layer, could be responsible for this phenomenon [9, 27]. Shi et al. [105] reported time-dependent delamination of a protective inhibitor layer on AA2024. They observed intensive corrosion of AA2024 substrate due to degeneration of the cerium cinnamate inhibitor layer in saline solution after 13 days.

LPR and PDS results identified the barrier properties of the inhibitor complex layer and its stability for longer immersion times. For the inhibited system, a decrease in $R_{\text {pol }}$ values can be attributed to possible porosity within the complex protective layer that allows ingress of the electrolyte and contributes to enhanced $i_{\text {corr }}$ values. These findings also corroborate the EIS results as the $R_{\mathrm{pol}}$ values calculated from EECs (Table 2) differentiate within a reasonable limit. Polarization resistance values evident for the $1 \mathrm{~d}$ inhibited sample by LPR measurement was $\approx 3.1 \times 10^{6}$ to $4.2 \times 10^{6} \Omega \mathrm{cm}^{2}$ which was calculated $7.2 \times 10^{6} \Omega \mathrm{cm}^{2}$ from EEC (Table 2). $R_{\text {pol }}$ values found to be almost identical for 7 days and 14 days inhibited samples by both EIS and LPR techniques. These findings support the argument that with increasing time, the inhibitor-induced layer developed pores and reduced its surface coverage that favors the charge transfer processes, i.e. higher $i_{\text {corr }}$ values. A gradual rise in current 
density from 0.012 to $0.028 \mathrm{~mA} \mathrm{~cm}^{-2}$ after 14 days is also supported by the explanation of the increase in charge transfer activities in the coating-substrate interface. Additionally, these findings agree with the PDS results as $R_{\mathrm{pol}}$ significantly increased for inhibited conditions, compared with uninhibited conditions, that resulted in reduced current density.

The PDS curves showed lower $i_{\text {corr }}$ value for the inhibited system in 1 day immersed sample (Fig. 2b). This could be assigned to the emergence of a porous inhibitor film, offering a passable barrier to corrosion after 1 day immersion. Higher $i_{\text {corr }}$ values could be attributed to the filling up of porous cathodic sites with corrosion products, thus facilitating re-passivation processes and lowering the current density overall. Aballe et al. [111] have provided similar observations for AA5083 alloy in 3.5\% NaCl solution. They reported substantial oxide film growth with immersion time that contributed to the re-passivation process. Rapid film formation in the inhibited system possibly contributed to the low $i_{\text {corr }}$ values, initially observed at 1 day. However, the likelihood of a time-dependent degradation of the inhibitorinduced film/layer resulted in lower $i_{\text {corr }}$ values at 14 days. The shift of Tafel curves to more negative $\mathrm{E}_{\text {corr }}$ values in inhibited conditions with time indicates a predominant cathodic character of 2-MBI on AA6061.

\subsection{Tentative correlation between $\mathrm{pH}$ and changes of electrochemical parameters}

The steep rise of $\mathrm{pH}$ in the uninhibited system and moderate rise in inhibited condition could be attributed to the degree of dissolution of aluminum oxide layer/protective inhibitor layer due to micro galvanic coupling between the aluminum matrix and intermetallic particles [112]. It has been postulated in earlier studies that the cathodic partial reactions facilitate the oxygen reduction and hydrogen evolution reactions on the alloy surface. It could increase the solution $\mathrm{pH}$ and promote anodic dissolution of $\mathrm{Al}$ and $\mathrm{Mg}$ from different IMPs comprised of $\mathrm{Cu}$ or Fe. Hydroxyl ion $\left(\mathrm{OH}^{-}\right)$generation enables a high $\mathrm{pH}$ environment that favors the dissolution of the aluminum oxide layer, gradually exposing the underneath alloy surface to the corrosive environment [23, $24]$. In this study, $E_{\text {corr }}$ values were found to be more positive for the inhibited conditions than uninhibited conditions. Pyun et al. [113] have suggested more negative $E_{\text {corr }}$ values for the uninhibited system than the inhibited system, referring to the loss of passivity of the AA6061 substrate. It could be related to thinning of the surface oxide layer by hydroxide ion $\left(\mathrm{OH}^{-}\right)$attack (alkaline chemical dissolution) or to the absence of the primary oxide film [113]. In the current study, the presence of inhibitor molecules could have provided a barrier effect that delayed the onset of micro galvanic coupling, i.e. lowering the dissolution of the oxide layer and stabilizing it further. It may have delayed the charge transfer reaction at the electrolyte/oxide-inhibitor film interface or the $\mathrm{Al}^{3+}$ ion transportation through the oxide film [114].

Furthermore, it can be appreciated in terms of LPR measurements, there is a fall in the $R_{\text {pol }}$ values in the inhibited system after 7 days, and it remains stable in between 7 and 14 days. This refers to the escalation of the dissolution activity of the system. This could result in unstable $\mathrm{pH}$ of the solution after 7 days and steeply displaced to more alkaline values at 14 days.

\subsection{Coverage of Fe and Si-rich IMPs, protection of the bulk, and tentative mechanism of inhibition}

Surface and electrochemical analysis results have postulated that in the inhibited sample, the protective film/layer over $\mathrm{Fe}$ and Si-rich IMPs supposedly prevented $\mathrm{Al}$ and $\mathrm{Mg}$ dealloying from these IMPs (Fig. 6c). It has been postulated that localized corrosion is usually initiated by a dealloying attack on IMPs but stabilizes (continuous corrosion) through nano galvanic interactions between regions rich in nobler metals and the IMPs. This phenomenon gradually promotes localized solution chemistry, diminishing the protective layer covering the nearby alloy matrix, leading to selective dissolution [115].

Adsorption of an organic inhibitor film could limit the activity of cathodically active nobler IMPs and restrain the anodic dissolution of active metals like $\mathrm{Al}$ and $\mathrm{Mg}[8,116]$. Kharitonov et al. [49] have investigated inorganic $\mathrm{Na}_{3} \mathrm{VO}_{4}$ (sodium orthovanadate) in saline solution on AA6063-T5 for $24 \mathrm{~h}$. They have and postulated corrosion inhibition mechanism by rapid film formation over the local cathodic sites created by Mg-rich intermetallic that suppressed the dissolution of $\mathrm{Mg}$ and protected the bulk from pitting corrosion. The inhibition process started with the reduction reaction of $\mathrm{NaVO}_{3}$ on the AA6063 surface. This reduction reaction helped form protective films of insoluble oxides and hydroxides over cathodic IMPs and slowed down anodic dissolution $[117,118]$. Similar but limited, studies for AAxxx alloys with organic inhibitors are available [9, 27]. Uncorroded Si-rich IMPs in the subsurface region of AA6061 were identified beneath the protective inhibitor layer (Fig. $6 \mathrm{~b}$ and d). The $\mathrm{Fe}$ and $\mathrm{Si}$-containing IMPs concealed by the protective layer exhibit no significant indication of trenching, confirmed by the absence of selective dissolution of $\mathrm{Al}$ or $\mathrm{Mg}$. The presence of weak $\mathrm{Cl}$ or $\mathrm{O}$ signals near the thick inhibitor layer further confirms that bulk $\mathrm{Al}$ was unaffected from anodic dissolution and cathodic reduction of $\mathrm{O}$ or $\mathrm{Cl}$. The continuity of the inhibitor layer remains unchanged up to 7 days, with the identical chemical composition observed at 1 day. However, the inhibitor layer's continuity was reduced at 14 days, which confirms the time-dependent degradation 
of protectiveness of 2-MBI and supports the findings of electrochemical data.

The thickness of the protective layer over AA6061 is much thicker ( $3.3 \mathrm{~nm}$ from XPS etching) than the monolayer thickness of 2-MBI molecules and the thickness of the naturally occurring oxide layer of aluminum alloys [52, 89]. In addition, the layer is comprised of atom species from 2-MBI inhibitor with traces of O. Therefore; this layer could be a complex of physically absorbed 2-MBI molecules or a complex layer formed through the interaction of inhibitor molecules with available surface oxygenated species. Moreover, instead of a mono layer, multiple layers of a complex inhibitor system have formed. The EDS results are consistent with the findings of EIS results regarding the presence of a thick protective/barrier layer that has delayed the ionic diffusion process and protected IMPs from corrosion attack [43]. In the latest study [119], 2-MBI film formed over $\mathrm{Cu}$ surface has been investigated by density functional theory, and insitu surface characterization was employed to strengthen the findings of molecular-level modeling. It has been proposed that 2-MBI could interact with oxide-covered $\mathrm{Cu}$ surface by $\mathrm{S}$ in the form of thione or thiolate, whereas $\mathrm{N}$ could interact in the form of pyrrole and pyridine. A multilayer film structure has been proposed where the first layer is chemically absorbed, followed by multiple layers of the $\mathrm{Cu}-\mathrm{MBI}$ complex. Our results are slightly aligned with these findings as the XPS has revealed oxide and metal peaks of $\mathrm{Al}$ in the inhibitor-induced layer. The chemical shifts of the S and N environment from outermost to innermost layer also presumably corroborates the existence of the Al-2MBI complex in the coating-solution interface, which gets thicker and porous with time.

The changes of N $1 \mathrm{~s}$ and S 2p XPS spectra for the inhibited AA6061 confirms the chemisorption of 2-MBI molecules in the innermost layer. It could be rational to predict that $\mathrm{N}$ and $\mathrm{S}$ atoms have participated in the attachment of 2-MBI to the substrate surface. Based on previous articles, the tentative mechanism revealed from the XPS etching results could be expected. It was reported that $S$ could be firmly adsorbed to the substrate surface (S-Al) and masked the bulk from corrosion [43]. It has been reported that 2-MBI in thione form could be adsorbed on Au surface in a solution having $\mathrm{pH}>2$ with an upward geometry [28]. However, the molecular orientation is beyond the scope of the current study as angle-resolved XPS has not been performed. Moreover, this arrangement is improbable for this study as $\mathrm{N}$ atoms (one or both) could be attached with AA6061 substrate. On the contrary, $\mathrm{C}$ atoms from the benzene ring were not observed to participate in the molecular attachment of 2-MBI with AA6061. Gas cluster ion beam sputtering associated with XPS measurements indicated two different 2-MBI molecules bonding in the surface layer, i.e. the topmost position contains 2-MBI molecules, i.e. physically absorbed ones. Later, the organometallic complexes have been thought to be formed via $\mathrm{S}$ and $\mathrm{N}$ interactions with $\mathrm{Al}$.

The chemical interaction of an inhibitor molecule with a heterogeneous alloy surface and its durability in a corrosive electrolyte were the focus of this study, according to the thematic illustration of Fig. 1. Results have suggested that 2-MBI primarily interacted with AA6061 with S and $\mathrm{N}$ atoms in two different bonding environments to form a multilayer film, varying structurally from coating-solution interface to metal-coating interface. 2-MBI could simultaneously interact with metal or oxide layer and adsorb over AA6061 to enhance the protectiveness of the alloy surface up to 1 day against ionic diffusion, water adsorption, etc. The existence of this layer has masked the activity of IMPs to form localized corrosion cells and retarded the anodic dissolution of bulk Al. Adsorption of 2-MBI has resulted in higher polarization resistance. The highest contribution from film resistance $\left(R_{\text {pore }}\right)$ is observed at 1 day and gradually drops further by supposedly breaking bonds between 2-MBI and the surface.

Consequently, after 7 and 14 days, this inhibitor film/layer became defective and thicker, allowing the transportation of aggressive ions through the porous structure to alloy surface, i.e. higher current density and low polarization resistance. The moderate rise in $\mathrm{pH}$ values indicates a possibility of a higher oxygen reduction rate at longer exposure times which may result in the quick breakdown of the oxide layer or any protective layer. However, the exact reasonings of timedependent degradation of the 2-MBI film are worth deeper in-situ experimental investigations.

\section{Conclusions}

This study elucidates the role of 2-MBI molecules in forming a protective layer over AA6061, identifying barrier properties of 2-MBI against electrolyte diffusion and the durability of inhibition over an exposure period of 14 days. EIS and LPR results indicated the emergence of a complex protective layer in the presence of the inhibitor, confirmed by the broad phase angle maxima at the middle-frequency range. This protective film/layer was stable up to 1 day, which became defective with a gradual drop in $R_{\text {charge-transfer }}$ and $R_{\text {pore }}$ values. A gradual reduction in inhibition efficiency from 64.7 to $21.0 \%$ after 14 days further confirms the ingress of electrolyte through the complex inhibitor layer. FIB-SEM and high-resolution TEM unveil the formation of a complex and multilayered structure of the protective film that consists of species associated with the inhibitor, i.e. $\mathrm{S}, \mathrm{N}$, and $\mathrm{C}$, in addition to surface oxygen. It has covered the nobler IMPs $(\mathrm{Fe} \& \mathrm{Si})$ and reduced the propensity of anodic dissolution of bulk Al. XPS etching results confirm the changes in bonding states of $\mathrm{S}$ to attach with $\mathrm{Al}$ and $\mathrm{N}$ have also been found 
in two different chemical environments. XPS results indicate the chemical and subsequent physical adsorption of 2-MBI molecules over AA6061, where the first interaction thought to be occurred by $\mathrm{S}$ and $\mathrm{N}$ from 2-MBI molecules. The latter could be a complex of Al-2MBI, or only the physically absorbed 2-MBI molecules coexisted with surface oxides. In summary, 2-MBI molecules formed a complex layer of $\sim 3 \mathrm{~nm}$ over AA6061 substrate with the available surface oxygenated species that successfully protected the bulk from corrosion attack up to $1 \mathrm{~d}$, beyond which this layer becomes more defective and less protective, over time due to diffusion of aggressive ions.

Supplementary Information The online version contains supplementary material available at https://doi.org/10.1007/s10800-022-01687-w.

Acknowledgements The authors are grateful to RMIT Microscopy and Microanalysis Facility (RMMF) for providing necessary guidance during FIB-SEM and XPS analysis.

Funding Open Access funding enabled and organized by CAUL and its Member Institutions.

Open Access This article is licensed under a Creative Commons Attribution 4.0 International License, which permits use, sharing, adaptation, distribution and reproduction in any medium or format, as long as you give appropriate credit to the original author(s) and the source, provide a link to the Creative Commons licence, and indicate if changes were made. The images or other third party material in this article are included in the article's Creative Commons licence, unless indicated otherwise in a credit line to the material. If material is not included in the article's Creative Commons licence and your intended use is not permitted by statutory regulation or exceeds the permitted use, you will need to obtain permission directly from the copyright holder. To view a copy of this licence, visit http://creativecommons.org/licenses/by/4.0/.

\section{References}

1. Visser P et al (2017) Electrochemical evaluation of corrosion inhibiting layers formed in a defect from lithium-leaching organic coatings. J Electrochem Soc 164(7):C396

2. Yu H-C et al (2008) Investigation of the trivalent-chrome coating on 6063 aluminum alloy. Mater Lett 62(17-18):2828-2831

3. Coelho L, Cossement D, Olivier M-G (2018) Benzotriazole and cerium chloride as corrosion inhibitors for AA2024-T3: an EIS investigation supported by SVET and ToF-SIMS analysis. Corros Sci 130:177-189

4. Cohen S (1995) Replacements for chromium pretreatments on aluminum. Corrosion 51(1):71-78

5. Lamin A et al (2022) Quorum sensing inhibitors applications: A new prospect for mitigation of microbiologically influenced corrosion. Bioelectrochemistry 145:108050

6. Nnaji $\mathrm{N}$ et al (2019) Inhibition of aluminium corrosion using benzothiazole and its phthalocyanine derivative. Electrocatalysis 10(4):445-458

7. Iannuzzi M, Frankel G (2007) Inhibition of aluminum alloy 2024 corrosion by vanadates: an in situ atomic force microscopy scratching investigation. Corrosion 63(7):672-688
8. Xhanari K, Finšgar M (2019) Organic corrosion inhibitors for aluminum and its alloys in chloride and alkaline solutions: a review. Arab J Chem 12(8):4646-4663

9. McMurray $\mathrm{H}$ et al (2010) The kinetics and mechanisms of filiform corrosion on aluminium alloy AA6111. Electrochim Acta 55(27):7843-7852

10. Liu X (2007) Filiform corrosion attack on pretreated aluminum alloy with tailored surface of epoxy coating. Corros Sci 49(9):3494-3513

11. King PC et al (2012) FIB/SEM study of AA2024 corrosion under a seawater drop, part II. Corros Sci 55:116-125

12. Finšgar MJ (2013) 2-Mercaptobenzimidazole as a copper corrosion inhibitor: Part II. Surface analysis using X-ray photoelectron spectroscopy. Corros Sci 72:90-98

13. Castner DG, Hinds K, Grainger DW (1996) X-ray photoelectron spectroscopy sulfur $2 p$ study of organic thiol and disulfide binding interactions with gold surfaces. Langmuir 12(21):5083-5086

14. Kairy SK, Birbilis N (2020) Clarifying the role of $\mathrm{Mg}_{2} \mathrm{Si}$ and $\mathrm{Si}$ in localized corrosion of aluminum alloys by quasi in situ transmission electron microscopy. Corrosion 76(5):464-475

15. Zhang Y et al (2014) Development of continuous cooling precipitation diagrams for aluminium alloys AA7150 and AA7020. J Alloys Compd 584:581-589

16. Jakeria MR, Ward L, Cole I (2021) Long term durability studies on the corrosion inhibition effect of 2-mercaptobenzimidazole (C3H4N2S) on AA6022: mechanism of film formation and influence of IMPs. Surf Interfaces 25:101164

17. Abo-Zeid E, Kim Y-T (2010) Investigation of developed precipitates in $\mathrm{AlMgSiCu}$ alloys with and without excess Si. Mater Sci Technol 26(4):440-444

18. Schumacher P et al (2015) Quench-induced precipitates in Al-Si alloys: calorimetric determination of solute content and characterisation of microstructure. Thermochim Acta 602:63-73

19. Sukiman N et al (2012) Durability and corrosion of aluminium and its alloys: overview, property space, techniques and developments. Alum Alloys-New Trends Fabr Appl 5:47-97

20. Zhu D, van Ooij WJ (2003) Corrosion protection of AA 2024-T3 by bis-[3-(triethoxysilyl) propyl] tetrasulfide in neutral sodium chloride solution. Part 1: corrosion of AA 2024-T3. Corros Sci 45(10):2163-2175

21. Larsen MH et al (2009) Effect of excess silicon and small copper content on intergranular corrosion of 6000-series aluminum alloys. J Electrochem Soc 157(2):C61

22. Svenningsen $\mathrm{G}$ et al (2006) Effect of thermomechanical history on intergranular corrosion of extruded $\mathrm{AlMgSi}(\mathrm{Cu})$ model alloy. Corros Sci 48(12):3969-3987

23. Zhou X et al (2012) Study of localized corrosion in AA2024 aluminium alloy using electron tomography. Corros Sci 58:299-306

24. Glenn A et al (2011) Corrosion of AA2024-T3 Part III: propagation. Corros Sci 53(1):40-50

25. Gharbi O, Birbilis N (2018) Clarifying the dissolution mechanisms and electrochemistry of $\mathrm{Mg}_{2} \mathrm{Si}$ as a function of solution pH. J Electrochem Soc 165(9):C497-C501

26. Li J, Birbilis N, Buchheit RG (2015) Electrochemical assessment of interfacial characteristics of intermetallic phases present in aluminium alloy 2024-T3. Corros Sci 101:155-164

27. Liu $\mathrm{Y}$ et al (2007) Precipitation in an AA6111 aluminium alloy and cosmetic corrosion. Acta Mater 55(1):353-360

28. Damej $\mathrm{M}$ et al (2021) The corrosion inhibition and adsorption behavior of mercaptobenzimidazole and bis-mercaptobenzimidazole on carbon steel in $1.0 \mathrm{M} \mathrm{HCl}$ : experimental and computational insights. Surf Interfaces 24:101095

29. Wang D et al (2021) Inhibitive effect of sodium molybdate on corrosion behaviour of AA6061 aluminium alloy in simulated concrete pore solutions. Constr Build Mater 270:121463 
30. Asl RM, Yousefpour M, Shanaghi A (2021) The investigation of corrosion behavior of $\mathrm{ZrO} 2-\mathrm{Al} 2 \mathrm{O} 3$-inhibitor/AA2024 nanocomposite thin film using sol-gel and AHP-TOPSIS method. Mater Chem Phys 262:124220

31. Mo Q et al (2021) Layer-by-layer self-assembled polyurea layers onto MAO surface for enhancing corrosion protection to aluminum alloy 6063. Surf Coat Technol 405:126653

32. Mostafa M et al (2021) Molecular structure aspects and molecular reactivity of some triazole derivatives for corrosion inhibition of aluminum in $1 \mathrm{M} \mathrm{HCl}$ solution. J Mol Struct 1236:130292

33. Mohammadi I et al (2020) Sodium diethyldithiocarbamate as a novel corrosion inhibitor to mitigate corrosion of 2024-T3 aluminum alloy in $3.5 \mathrm{wt} \% \mathrm{NaCl}$ solution. J Mol Liq 307:112965

34. Ciucci F (2019) Modeling electrochemical impedance spectroscopy. Curr Opin Electrochem 13:132-139

35. Jasim RA et al (2020) Nano-Parctials as corrosion inhibitors for Aluminum alloys in acidic solution at different Temperatures. IOP Conf Ser Mater Sci Eng 928:052014

36. Jiang $\mathrm{H}$ et al (2020) Inhibition effect and mechanism of inorganic-organic hybrid additives on three-dimension porous aluminum foam in alkaline Al-air battery. J Power Sources 448:227460

37. Sacco A (2017) Electrochemical impedance spectroscopy: fundamentals and application in dye-sensitized solar cells. Renew Sustain Energy Rev 79:814-829

38. Chauhan DS, Verma C, Quraishi M (2021) Molecular structural aspects of organic corrosion inhibitors: experimental and computational insights. J Mol Struct 1227:129374

39. Kozlica DK, Kokalj A, Milošev I (2021) Synergistic effect of 2-mercaptobenzimidazole and octylphosphonic acid as corrosion inhibitors for copper and aluminium-an electrochemical, XPS, FTIR and DFT study. Corros Sci 182:109082

40. Lai X et al (2021) Chitosan derivative corrosion inhibitor for aluminum alloy in sodium chloride solution: a green organic/ inorganic hybrid. Carbohydr Polym 265:118074

41. El Mazyani A, Chafi M, Essahli M (2021) Assessment of AA5005 aluminum alloy corrosion resistance by Direct Blue 15 inhibitor in sodium chloride medium. Mater Today: Proc 37:3882-3888

42. Damej $\mathrm{M}$ et al (2021) Experimental and theoretical explorations of S-alkylated mercaptobenzimidazole derivatives for use as corrosion inhibitors for carbon steel in $\mathrm{HCl}$. J Mol Liq 331:115708

43. Neupane $S$ et al (2021) Study of mercaptobenzimidazoles as inhibitors for copper corrosion: down to the molecular scale. J Electrochem Soc 168(5):051504

44. Finšgar M (2020) Advanced surface analysis using GCIBC60++-tandem-ToF-SIMS and GCIB-XPS of 2-mercaptobenzimidazole corrosion inhibitor on brass. Microchem J 159:105495

45. Metikoš-Huković M, Babić R, Marinović A (1998) Spectrochemical characterization of benzotriazole on copper. J Electrochem Soc 145(12):4045

46. Williams G, Coleman AJ, McMurray HN (2010) Inhibition of aluminium alloy AA2024-T3 pitting corrosion by copper complexing compounds. Electrochim Acta 55(20):5947-5958

47. Zheludkevich $\mathrm{M}$ et al (2005) Triazole and thiazole derivatives as corrosion inhibitors for AA2024 aluminium alloy. Corros Sci 47(12):3368-3383

48. Recloux I et al (2018) Stability of benzotriazole-based films against AA2024 aluminium alloy corrosion process in neutral chloride electrolyte. J Alloys Compd 735:2512-2522

49. Kharitonov D et al (2017) Corrosion inhibition of AA6063 alloy by vanadates in alkaline media: Korrosionsinhibierung der Aluminiumlegierung AA6063 in alkalischen Medien durch Vanadate. Mater Sci Eng Technol 48(7):646-660

50. Kharitonov DS et al (2019) Corrosion inhibition of aluminium alloy AA6063-T5 by vanadates: local surface chemical events elucidated by confocal Raman micro-spectroscopy. Corros Sci 148:237-250

51. Vernack E et al (2020) DFT studies of 2-mercaptobenzothiazole and 2-mercaptobenzimidazole as corrosion inhibitors for copper. Corros Sci 174:108840

52. Kovačević N, Kokalj A (2011) Analysis of molecular electronic structure of imidazole-and benzimidazole-based inhibitors: a simple recipe for qualitative estimation of chemical hardness. Corros Sci 53(3):909-921

53. Harvey $T$ et al (2011) The effect of inhibitor structure on the corrosion of AA2024 and AA7075. Corros Sci 53(6):2184-2190

54. Visser P, Terryn H, Mol JM (2018) On the importance of irreversibility of corrosion inhibitors for active coating protection of AA2024-T3. Corros Sci 140:272-285

55. Abreu-Quijano $\mathrm{M}$ et al (2011) Quantum chemical study of 2-mercaptoimidazole, 2-mercaptobenzimidazole, 2-mercapto-5-methylbenzimidazole and 2-mercapto-5-nitrobenzimidazole as corrosion inhibitors for steel. Int J Electrochem Sci 6(9):3729-3742

56. Assouli B, Srhiri A, Idrissi H (2004) Effect of 2-mercaptobenzimidazole and its polymeric film on the corrosion inhibition of brass (60/40) in ammonia solution. Corrosion 60(4):399-407

57. Chadwick D, Hashemi T (1979) Electron spectroscopy of corrosion inhibitors: surface films formed by 2 -mercaptobenzothiazole and 2-mercaptobenzimidazole on copper. Surf Sci 89(1-3):649-659

58. Antonijević MM, Milić SM, Petrović MB (2009) Films formed on copper surface in chloride media in the presence of azoles. Corros Sci 51(6): 1228-1237

59. Bahrami K, Khodaei MM, Soheilizad M (2009) A novel, practical synthesis of sulfonyl chlorides from thiol and disulfide derivatives. Synlett 2009(17):2773-2776

60. Bain CD, Biebuyck HA, Whitesides GM (1989) Comparison of self-assembled monolayers on gold: coadsorption of thiols and disulfides. Langmuir 5(3):723-727

61. Palomino LEM et al (2007) Investigation of the corrosion behaviour of a bilayer cerium-silane pre-treatment on $\mathrm{Al} 2024-\mathrm{T} 3$ in $0.1 \mathrm{M} \mathrm{NaCl}$. Electrochim Acta 52(27):7496-7505

62. Panagopoulos CN, Georgiou EP, Gavras AG (2009) Corrosion and wear of 6082 aluminum alloy. Tribol Int 42(6):886-889

63. El-Shafei AA, Moussa MNH, El-Far AA (1997) Inhibitory effect of amino acids on $\mathrm{Al}$ pitting corrosion in $0.1 \mathrm{~m} \mathrm{NaCl}$. J Appl Electrochem 27(9):1075-1078

64. Popova A et al (2003) AC and DC study of the temperature effect on mild steel corrosion in acid media in the presence of benzimidazole derivatives. Corros Sci 45(1):33-58

65. Finšgar M (2013) 2-Mercaptobenzimidazole as a copper corrosion inhibitor: Part I. Long-term immersion, 3D-profilometry, and electrochemistry. Corros Sci 72:82-89

66. Kairy $\mathrm{S}$ et al (2017) On the electrochemical and quasi in situ corrosion response of the Q-phase (AlxCuyMgzSiw) intermetallic particle in 6xxx series aluminum alloys. Corrosion 73(1):87-99

67. McMurray H et al (2007) Scanning kelvin probe studies of filiform corrosion on automotive aluminum alloy AA6016. J Electrochem Soc 154(7):C339

68. Ghasemlou M et al (2020) Use of synergistic interactions to fabricate transparent and mechanically robust nanohybrids based on starch, non-isocyanate polyurethanes, and cellulose nanocrystals. ACS Appl Mater Interfaces 12(42):47865-47878

69. Jamil HE et al (2005) Corrosion behaviour of reinforcing steel exposed to an amino alcohol based corrosion inhibitor. Cement Concr Compos 27(6):671-678

70. Perez N (2004) Electrochemistry and corrosion science, vol 412. Springer, Berlin

71. Instruments $G$ (2007) Basics of electrochemical impedance spectroscopy. G instruments, complex impedance in Corrosion. Gamry Instruments, Warminster, pp 1-30 
72. Liu X et al (2009) Study on corrosion electrochemical behavior of several different coating systems by EIS. Prog Org Coat 64(4):497-503

73. Thompson I, Campbell D (1994) Interpreting Nyquist responses from defective coatings on steel substrates. Corros Sci 36(1):187-198

74. Jüttner K (1990) Electrochemical impedance spectroscopy (EIS) of corrosion processes on inhomogeneous surfaces. Electrochim Acta 35(10):1501-1508

75. Deflorian F, Rossi S (2006) An EIS study of ion diffusion through organic coatings. Electrochim Acta 51(8):1736-1744

76. Dehri I, Erbil M (2000) The effect of relative humidity on the atmospheric corrosion of defective organic coating materials: an EIS study with a new approach. Corros Sci 42(6):969-978

77. Margarit-Mattos ICP (2020) EIS and organic coatings performance: revisiting some key points. Electrochim Acta 354:136725

78. Mahdavian M, Ashhari S (2010) Corrosion inhibition performance of 2-mercaptobenzimidazole and 2-mercaptobenzoxazole compounds for protection of mild steel in hydrochloric acid solution. Electrochim Acta 55(5):1720-1724

79. Gao H et al (2010) High efficiency corrosion inhibitor 8-hydroxyquinoline and its synergistic effect with sodium dodecylbenzenesulphonate on AZ91D magnesium alloy. Corros Sci 52(5):1603-1609

80. Hsu C, Mansfeld F (2001) Concerning the conversion of the constant phase element parameter Y0 into a capacitance. Corrosion 57(9):747-748

81. Badea G et al (2010) Polarisation measurements used for corrosion rates determination. J Sustain Energy 1(1):1-4

82. Hernandez-Alvarado LA, Hernandez LS, Rodriguez-Reyna SL (2012) Evaluation of corrosion behavior of galvanized steel treated with conventional conversion coatings and a chromatefree organic inhibitor. Green Approaches Corros Mitig 2012:21

83. Kumari PR et al (2011) 3-Methyl-4-amino-5-mercapto-1, 2, 4-triazole as corrosion inhibitor for $6061 \mathrm{Al}$ alloy in $0.5 \mathrm{M}$ sodium hydroxide solution. J Coat Technol Res 8(6):685

84. Kairy $S$ et al (2017) On the intergranular corrosion and hardness evolution of 6xxx series $\mathrm{Al}$ alloys as a function of $\mathrm{Si}: \mathrm{Mg}$ ratio, $\mathrm{Cu}$ content, and aging condition. Corrosion 73(10):1280-1295

85. Shi A, Shaw B, Sikora E (2005) The role of grain boundary regions in the localized corrosion of a copper-free 6111-like aluminum alloy. Corrosion 61(6):534-547

86. Eckermann F et al (2008) The influence of MgSi particle reactivity and dissolution processes on corrosion in $\mathrm{Al}-\mathrm{Mg}-\mathrm{Si}$ alloys. Electrochim Acta 54(2):844-855

87. Kosari A et al (2020) Dealloying-driven local corrosion by intermetallic constituent particles and dispersoids in aerospace aluminium alloys. Corros Sci 177:108947

88. King PC et al (2011) FIB/SEM study of AA2024 corrosion under a seawater drop: part I. Corros Sci 53(3):1086-1096

89. Strohmeier BR (1990) An ESCA method for determining the oxide thickness on aluminum alloys. Surf Interface Anal 15(1):51-56

90. Abdureyim A et al (2001) Characterization of 4-mercaptohydrocynnamic acid self-assembled film on Au (111) by means of X-ray photoelectron spectroscopy. J Electron Spectrosc Relat Phenom 114:371-374

91. Whelan CM, Smyth MR, Barnes CJ (1999) HREELS, XPS, and electrochemical study of benzenethiol adsorption on Au (111). Langmuir 15(1):116-126

92. Finšgar M et al (2009) Electrochemical and XPS study of polyethyleneimines of different molecular sizes as corrosion inhibitors for AISI 430 stainless steel in near-neutral chloride media. Mater Chem Phys 116(1):198-206
93. Finšgar M et al (2009) Polyethyleneimine as a corrosion inhibitor for ASTM 420 stainless steel in near-neutral saline media. Corros Sci 51(3):525-533

94. Finšgar M, Kovač J, Milošev I (2009) Surface analysis of 1-hydroxybenzotriazole and benzotriazole adsorbed on $\mathrm{Cu}$ by X-ray photoelectron spectroscopy. J Electrochem Soc 157(2):C52

95. Finšgar M (2021) The interface characterization of 2-mercapto1 -methylimidazole corrosion inhibitor on brass. Coatings 11(3):295

96. Laiho $\mathrm{T}$ et al (2005) Photoelectron spectroscopy study of irradiation damage and metal-sulfur bonds of thiol on silver and copper surfaces. J Electron Spectrosc Relat Phenom 142(2):105-112

97. Yoshida T (1980) An X-ray photoelectron spectroscopic study of several metal complexes of 2-mercaptobenzimidazole and 2-mercaptobenzoxazole. Bull Chem Soc Jpn 53(5):1449-1450

98. Rosink J et al (2000) Self-assembly of $\pi$-conjugated azomethine oligomers by sequential deposition of monomers from solution. Langmuir 16(10):4547-4553

99. Peng MC et al (2004) Studies of sulfonated polyethylene for biliary stent application. J Appl Polym Sci 92(4):2450-2457

100. Lin JC, Chuang WH (2000) Synthesis, surface characterization, and platelet reactivity evaluation for the self-assembled monolayer of alkanethiol with sulfonic acid functionality. J Biomed Mater Res 51(3):413-423

101. Laibinis PE et al (1991) Comparison of the structures and wetting properties of self-assembled monolayers of $n$-alkanethiols on the coinage metal surfaces, copper, silver, and gold. J Am Chem Soc 113(19):7152-7167

102. Materazzi S et al (2012) TG-MS and TG-FTIR studies of imidazole-substituted coordination compounds: Co (II) and Ni (II)complexes of bis (1-methylimidazol-2-yl) ketone. Thermochim Acta 543:183-187

103. Ergun Ü, Emregül KC (2014) Azole compounds as corrosion inhibitors: part I. J Mater Eng Perform 23(1):213-221

104. Kovačević N, Milošev I, Kokalj A (2015) The roles of mercapto, benzene, and methyl groups in the corrosion inhibition of imidazoles on copper: II. Inhibitor-copper bonding. Corros Sci 98:457-470

105. Visser $\mathrm{P}$ et al (2016) Lithium salts as leachable corrosion inhibitors and potential replacement for hexavalent chromium in organic coatings for the protection of aluminum alloys. J Coat Technol Res 13(4):557-566

106. Shi H, Han E-H, Liu F (2011) Corrosion protection of aluminium alloy 2024-T3 in $0.05 \mathrm{M} \mathrm{NaCl}$ by cerium cinnamate. Corros Sci 53(7):2374-2384

107. Prakashaiah B et al (2018) Corrosion inhibition of 2024-T3 aluminum alloy in $3.5 \% \mathrm{NaCl}$ by thiosemicarbazone derivatives. Corros Sci 136:326-338

108. Yasakau K, Zheludkevich M, Ferreira M (2018) Role of intermetallics in corrosion of aluminum alloys. Smart corrosion protection. In: Kumar KS, Bao G (eds) Intermetallic matrix composites. Elsevier, Amsterdam, pp 425-462

109. Hosseini M, Tavakoli H, Shahrabi T (2008) Synergism in copper corrosion inhibition by sodium dodecylbenzenesulphonate and 2-mercaptobenzoimidazole. J Appl Electrochem 38(11):1629-1636

110. McCafferty E, Hackerman N (1972) Double layer capacitance of iron and corrosion inhibition with polymethylene diamines. J Electrochem Soc 119(2):146

111. Aballe A et al (2001) Localized alkaline corrosion of alloy AA5083 in neutral 3.5\% $\mathrm{NaCl}$ solution. Corros Sci 43(9): 1657-1674

112. Lacroix L et al (2012) Simulating the galvanic coupling between $\mathrm{S}-\mathrm{Al}_{2} \mathrm{CuMg}$ phase particles and the matrix of 2024 aerospace aluminium alloy. Corros Sci 64:213-221 
113. Pyun S-I et al (1999) Effects of Cl-, NO- 3 and $\mathrm{SO}_{2}-4$ ions on anodic dissolution of pure aluminum in alkaline solution. Corros Sci 41(4):653-667

114. Brown O, Whitley J (1987) Electrochemical behaviour of aluminium in aqueous caustic solutions. Electrochim Acta 32(4):545-556

115. Kosari A et al (2020) In-situ nanoscopic observations of dealloying-driven local corrosion from surface initiation to in-depth propagation. Corros Sci 177:108912

116. Balaskas AC, Curioni M, Thompson GE (2020) Corrosion protection mechanism of 2-mercaptobenzothiazole and its potential synergistic effect with cerium ions for treatment of AA 2024-T3. J Electroanal Chem 863:114081

117. Kendig M, Buchheit R (2003) Corrosion inhibition of aluminum and aluminum alloys by soluble chromates, chromate coatings, and chromate-free coatings. Corrosion 59(5):379-400
118. Lopez-Garrity O, Frankel G (2014) Corrosion inhibition of aluminum alloy 2024-T3 by sodium molybdate. J Electrochem Soc 161(3):C95-C106

119. Kozlica DK, Kokalj A, Milošev I (2021) Synergistic effect of 2-mercaptobenzimidazole and octylphosphonic acid as corrosion inhibitors for copper and aluminium-an electrochemical, XPS, FTIR and DFT study. Corros Sci 182:109082

Publisher's Note Springer Nature remains neutral with regard to jurisdictional claims in published maps and institutional affiliations. 